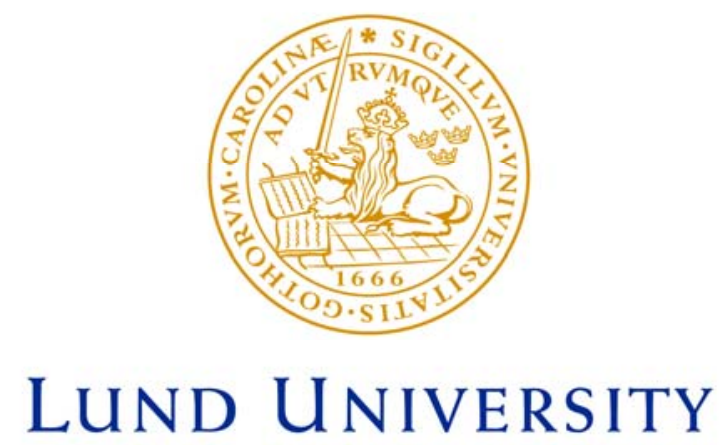

Faculty of Medicine

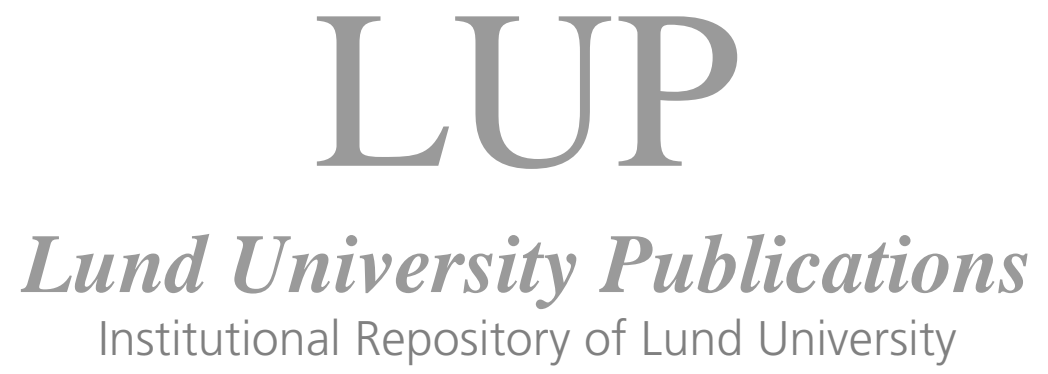

This is an author produced version of a paper published in Free radical biology \& medicine. This paper has been peerreviewed but does not include the final publisher proofcorrections or journal pagination.

Citation for the published paper:

Magnus Hansson, Roland Månsson, Saori Morota, Hiroyuki Uchino, Therese Kallur, Tetsuo Sumi, Nagao Ishii, Motohide Shimazu, Marcus F Keep,

Alexandr Jegorov, Eskil Elmér.

"Calcium-induced generation of reactive oxygen species in brain mitochondria is mediated by permeability transition."

Free radical biology \& medicine, 2008, Issue: April 23.

http://dx.doi.org/10.1016/j.freeradbiomed.2008.04.021

Access to the published version may require journal subscription.

Published with permission from: Elsevier 


\title{
Calcium-induced generation of reactive oxygen species in brain mitochondria is mediated by permeability transition
}

\author{
Magnus J. Hansson $^{a, *}$, Roland Månsson ${ }^{a, b}$, Saori Morota ${ }^{a, c, d}$, Hiroyuki Uchinoc, Thérese Kallure, \\ Tetsuo Sumif, Nagao Ishiic, Motohide Shimazuf, Marcus F. Keep ${ }^{\mathrm{g}}$, Alexandr Jegorov ${ }^{\mathrm{h}}$ and Eskil \\ Elmér ${ }^{\mathrm{a}}$
}

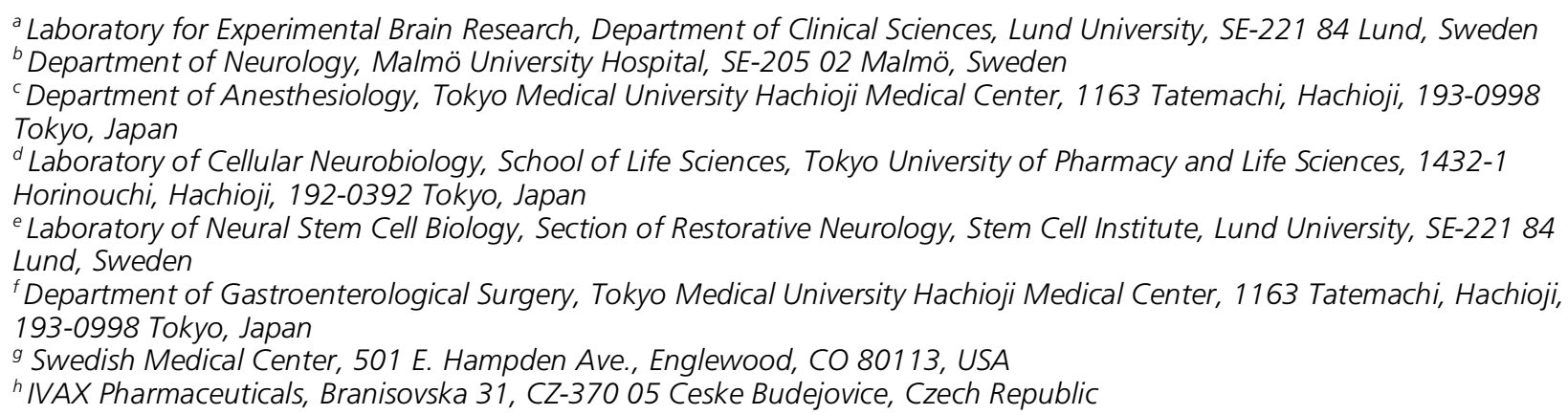

* Corresponding author: Magnus J. Hansson, Laboratory for Experimental Brain Research, Department of Clinical Sciences, Lund University, SE-221 84 Lund, Sweden. Tel: +46 462220605 , Fax: +46 462220615

E-mail address: magnus.hansson@med.lu.se

\begin{abstract}
Mitochondrial uptake of calcium in excitotoxicity is associated with subsequent increase in reactive oxygen species (ROS) generation and delayed cellular calcium deregulation in ischemic and neurodegenerative insults. The mechanisms linking mitochondrial calcium uptake and ROS production remain unknown but activation of the mitochondrial permeability transition ( $\mathrm{mPT}$ ) may be one such mechanism. In the present study, calcium increased ROS generation in isolated rodent brain and human liver mitochondria undergoing $\mathrm{mPT}$ despite an associated loss of membrane potential, NADH and respiration. Unspecific permeabilization of the inner mitochondrial membrane by alamethicin likewise increased ROS independently of calcium, and the ROS increase was further potentiated if $N A D(H)$ was added to the system. Importantly, calcium per se did not induce a ROS increase unless mPT was triggered. Twenty-one cyclosporin A analogs were evaluated for inhibition of calcium-induced ROS and their efficacy clearly paralleled their potency of inhibiting mPT-mediated mitochondrial swelling. We conclude that while intact respiring mitochondria possess powerful antioxidant capability, mPT induces a dysregulated oxidative state with loss of GSH- and NADPH-dependent ROS detoxification. We propose that $\mathrm{mPT}$ is a significant cause of pathological ROS generation in excitotoxic cell death.
\end{abstract}

Keywords: Reactive oxygen species, Mitochondria, Brain, Calcium, Excitotoxicity, Permeability transition, Cyclophilin, Neurodegeneration, GSH, Delayed calcium deregulation, Human, Respirometry

Abbreviations: Amplex red, N-acetyl-3,7-dihydroxyphenoxazine; ANOVA, one-way analysis of variance; BSA, bovine serum albumin; carboxy-PTIO = 2-(4-Carboxyphenyl)-4,4,5,5-tetramethylimidazoline-1-oxyl-3-oxide potassium salt; CCCP = carbonyl cyanide m-chlorophenylhydrazone; CDNB, 1-chloro-2,4 dinitrobenzene; CRC, calcium retention capacity; CSA, cyclosporin A; Cyt c, cytochrome c; $\Delta y$, mitochondrial membrane potential; $\Delta \mathrm{p}$, mitochondrial protonmotive force; DCF-DA, 2',7'dichlorodihydrofluorescein diacetate; DEBIO-025 = UNIL025, N-methyl-D-alanine-3-N-ethyl-valine-4-CsA; EGTA, ethylene glycol-bis(b-aminoethylether)-N,N,N',N'-tetraacetic acid; ETC, electron transport chain; GSH, glutathione; HRP, horseradish peroxidase; IB, isolation buffer; MeBmt, (2S,3R,4R,6E)-3-hydroxy-4-methyl-2-methylamino-6-octanoic acid; MOPS, 3-(NMorpholino)propanesulfonic acid; mPT, mitochondrial permeability transition; NAD(P)(H), pyridine nucleotides; NIM811, Nmethyl-4-isoleucine-CsA; NMDA, N-methyl-D-Aspartate; PTIO = 2-Phenyl-4,4,5,5-tetramethylimidazoline-1-oxyl 3-oxide; RCR, respiratory control ratio; ROS, reactive oxygen species; TMPD $=\mathrm{N}, \mathrm{N}, \mathrm{N}^{\prime}, \mathrm{N}^{\prime}$-Tetramethyl-p-phenylenediamine dihydrochloride 


\section{INTRODUCTION}

An excessive or sustained increase of reactive oxygen species (ROS) has been implicated in the pathogenesis of diseases as diverse as cancer, diabetes mellitus and atherosclerosis as well as in the mechanisms of senescence [1]. Mitochondrial generation of ROS participates in cell death cascades of both acute brain injuries and chronic neurodegenerative disease [2, 3]. Reactive oxygen species may play a physiological role in intracellular signaling, and function as second messengers in e.g. ischemic preconditioning $[1,4,5]$, but are potentially harmful as they are capable of oxidative modifications of proteins, nucleic acids, polysaccharides and lipid membranes [6]. Excitotoxicity is a pathological feature of both acute and chronic neurodegenerative conditions [7-9]. Increased ROS production from mitochondria has been demonstrated following NMDA receptor stimulation in models of excitotoxicity and has also been coupled to mitochondrial loading of calcium [10-15]. However, the mechanism linking mitochondrial calcium loading and ROS production is currently unresolved [15-17], and studies in isolated brain mitochondria have yielded diverging results regarding the effect of calcium on mitochondrial ROS generation [18-22]. Mitochondria are able to buffer cellular calcium transients and have high capacity for calcium retention under normal physiological conditions [23]. The calcium retention capacity of mitochondria is however greatly diminished by a reduction in energy metabolites, an oxidative state or a decreased mitochondrial proton gradient, and calcium overload may under such conditions trigger the so-called mitochondrial permeability transition (mPT) [24, 25]. The overt increase in permeability of the inner mitochondrial membrane caused by $\mathrm{mPT}$ activation results in an immediate loss of protonmotive force and an osmotic expansion of the matrix compartment with rupture of the outer membrane. This process is one proposed mechanism for mitochondrial release of proapoptotic proteins such as cytochrome $c$ (Cyt c) to the cytosol.

In the present study, we investigate calciuminduced ROS production in isolated non-synaptosomal brain mitochondria in relation to $\mathrm{mPT}$, redox state, loss of Cyt c, respiratory function and scavenging of $\mathrm{H}_{2} \mathrm{O}_{2}$. Further, we study the substrate dependency and regulation of ROS generation in permeabilized mitochondria. Cyclosporin A (CsA) and 21 of its natural and semisynthetic analogs are employed to correlate mPT inhibition with ROS generation from calciumexposed mitochondria. To confirm the generability of our findings we evaluate calcium-induced ROS release in isolated mitochondria from freshly resected human liver samples.

\section{Experimental Procedures}

Materials and tissues

Animal procedures were approved by the Malmö/Lund Ethical Committee for Animal Research (M221-03, M44-07). Adult male Wistar rats, 300-500 g, were allowed ad libitum access to water and food prior to use. Human liver tissue was obtained from 4 male patients, 56-65 years old, undergoing liver resection due to colorectal cancer metastases. The human study was approved by the Ethical Committee of Hachioji Medical Center, Tokyo Medical University, permit number 12-01, and complies with the World Medical Association Declaration of Helsinki - Ethical Principles for Medical Research Involving Human Subjects and the EU Convention for the Protection of Human Rights and Dignity of the Human Being with Regard to the Application of Biology and Medicine: Convention on Human Rights and Biomedicine.

Amplex Red and Rhodamine 123 were obtained from Molecular Probes (Eugene, OR), Percoll solution was obtained from Amersham Biosciences (Uppsala, Sweden). NIM811 was kindly provided by Peter Waldmeier at Novartis (Basel Switzerland) and DEBIO025 (UNIL025) by Jean-Maurice Dumont and Grégoire Vuagniaux at Debiopharm S.A. (Lausanne, Switzerland). Other analogs and Cyclosporin A (CsA) were commercial and experimental compounds of IVAXPharmaceuticals, Czech Republic. All other chemicals were from Sigma (St. Louis, MO).

\section{Isolation of brain and liver mitochondria}

Isolation of free, i.e. non-synaptosomal, rat and mouse brain mitochondria was achieved according to method B by Sims [26] as described previously [27]. Animals were decapitated and the brains were rapidly transferred into ice-cold isolation buffer (IB, $320 \mathrm{mM}$ Sucrose, $2 \mathrm{mM}$ EGTA, $10 \mathrm{mM}$ Trizma base, pH 7.4). Cortical tissue $(10-15 \% \mathrm{w} / \mathrm{v})$ was homogenized in $12 \%$ Percoll solution in IB, using a $2 \mathrm{ml}$ Kontes Teflon Homogenizer, size 19 (Vineland, NJ, USA). The suspension was layered on a discontinuous Percoll gradient and after centrifugation at $30700 \mathrm{~g}$ for $7 \mathrm{~min}$, the resulting layer at the 26 and $40 \%$ Percoll interface was collected and washed twice in IB in successive centrifugations without further additions. Liver mitochondria from rat, mouse and human resected material were isolated using differential centrifugation as described previously [27]. All tissues were prepared immediately following resection. For human liver tissue, only the normal parenchyma between metastases was collected. Briefly, liver tissue was homogenized in IB $(10 \% \mathrm{w} / \mathrm{v})$. The homogenate was exposed to an initial low-speed centrifugation (300 $\mathrm{g}$ for $10 \mathrm{~min}$ ) and the resultant supernatant was centrifuged at $7800 \mathrm{~g}$ for 5 min. The pellet was resuspended in $19 \%$ Percoll, centrifuged at $11300 \mathrm{~g}$ for $10 \mathrm{~min}$, resuspended again in IB followed by a last centrifugation at $7800 \mathrm{~g}$ for $5 \mathrm{~min}$. All isolation procedures were carried out under ice-cold conditions and the mitochondria were used within $5 \mathrm{~h}$ from animal decapitation or within $8 \mathrm{~h}$ following resection of the human liver tissue. Mitochondrial protein content was determined by the Bradford Assay.

\section{Mitochondrial light scattering and swelling}

A Perkin-Elmer Luminescence Spectrometer LS-50B (Emeryville, CA, USA) with a well plate reader 
or a temperature controlled cuvette holder was used for all fluorescence and light scattering measurements. Rat brain mitochondria or human liver mitochondria corresponding to $0.2 \mathrm{mg}$ protein were suspended in $2 \mathrm{ml}$ of KCl-based (125 mM KCl, $20 \mathrm{mM}$ Trizma base, $2 \mathrm{mM}$ $\mathrm{Pi}(\mathrm{K}), 1 \mathrm{mM} \mathrm{MgCl} 2,1 \mu \mathrm{M}$ EGTA, $\mathrm{pH}$ 7.2) or sucrosebased (250 mM sucrose, $20 \mathrm{mM}$ MOPS, $10 \mathrm{mM}$ Trizma base, $2 \mathrm{mM} \mathrm{Pi}(\mathrm{K}), 1 \mathrm{mM} \mathrm{MgCl} 2,1 \mu \mathrm{M}$ EGTA, pH 7.2) buffer at $37^{\circ} \mathrm{C}$. Approximately $20 \mu \mathrm{l} \mathrm{IB}$ was carried over with mitochondria to the experimental buffers. Mitochondrial permeability transition (mPT) was monitored by following the decrease in $90^{\circ}$ light scattering at $520 \mathrm{~nm}$ reflecting mitochondrial swelling. The populational extent of swelling was calculated as calcium-induced decrease in light scattering compared to that by the ionophore alamethicin $(10 \mu \mathrm{g} / \mathrm{ml})$ as described previously [27]. Experiments evaluating mPT inhibition by CsA and 21 natural or semi-synthetic cyclosporin analogs were performed under de-energized conditions as described earlier [27, 28]. Mitochondria were incubated in the presence of $10 \mathrm{nM}$ to $5 \mu \mathrm{M}$ of CsA-analogs or vehicle and the extent of light scattering decrease was compared to that by alamethicin after $5 \mathrm{~min}$ of $\mathrm{Ca}^{2+}$ exposure. The concentrations of $\mathrm{Ca}^{2+}$ for the different mitochondria were chosen so that swelling in controls with vehicle was around $80 \%$ of the alamethicin-induced swelling whereas $1 \mu \mathrm{M}$ CsA resulted in nearly full inhibition of swelling $(50 \mu \mathrm{M}$ for mouse brain, $100 \mu \mathrm{M}$ for rat brain and $200 \mu \mathrm{M}$ for rat liver mitochondria). This enabled evaluation of a wide range of $\mathrm{mPT}$ inhibition by the cyclosporin analogs. Analogs 1-15 (identity given in Table 1) were evaluated in both mouse brain and mouse liver mitochondria, analogs 16-19 in mouse liver mitochondria only and NIM811 and UNIL025 (renamed DEBIO-025) were evaluated previously in rat brain mitochondria [28]. To enable inter-experimental comparisons of all analogs their relative inhibition of calcium-induced $\mathrm{mPT}$ was compared to that of CsA, all at $1 \mu \mathrm{M}$.

\section{Mitochondrial production of reactive oxygen species}

Mitochondrial $\mathrm{H}_{2} \mathrm{O}_{2}$ production was detected by following the oxidation of $1 \mu \mathrm{M}$ Amplex Red (N-acetyl3,7-dihydroxyphenoxazine) to the fluorescent product resorufin in presence of horseradish peroxidase (HRP, $0.5 \mathrm{U} / \mathrm{ml}$ ) and superoxide dismutase (SOD, $20 \mathrm{U} / \mathrm{ml}$ ), the latter present to ensure that all superoxide, the primary ROS generated in mitochondria, was converted to $\mathrm{H}_{2} \mathrm{O}_{2}$. Excitation and emission wavelengths were set to $560 \mathrm{~nm}$ and $590 \mathrm{~nm}$, respectively. Known amounts of $\mathrm{H}_{2} \mathrm{O}_{2}$ were added to establish a calibration curve (in the presence of mitochondria without substrates). Amplex Red provided, in our hands, the greatest sensitivity of available $\mathrm{H}_{2} \mathrm{O}_{2}$ probes and yielded more reliable results than e.g. DCFDA, but had however itself some pitfalls. Several compounds induced mitochondria-independent oxidation of the probe. NADH induced oxidation at concentrations $\geq 10 \mu \mathrm{M}$, which has also been previously noted by Votyakova et al. [29]. Concentrations up to $1.5 \mu \mathrm{M}$ NADH were used in the Amplex Red assay and this had no detectable effect by itself in mitochondria-free buffer. Glutathione (GSH) and tert-butyl hydroperoxide could not be used in the ROS assays for the same reason. Notably, respiratory inhibitors had to be frozen in dimethyl sulfoxide (DMSO) and diluted to working stock solutions in ethanol daily to avoid unspecific oxidation of Amplex Red in the experiments. Rotenone and CDNB (1-chloro-2,4 dinitrobenzene, used to deplete mitochondrial GSH) were particularly prone to induce these artifacts.

\section{$N A D(P) H$, membrane potential and mitochondrial calcium retention}

The redox status of $\mathrm{NAD}(\mathrm{P}) \mathrm{H}$ was determined qualitatively by following its autofluorescence (ex. 340 $\mathrm{nm}$, em. $460 \mathrm{~nm}$ ). Experiments with antimycin A could not be performed in this assay as it interfered with the NAD(P)H autofluorescence. Rhodamine 123 (100 nM) was used to assess mitochondrial membrane potential, with excitation and emission set to $490 \mathrm{~nm}$ and $528 \mathrm{~nm}$, respectively. Mitochondrial calcium uptake and release was monitored by the excitation ratio (ex. 340/380 nm, em. $509 \mathrm{~nm}$ ) of the extramitochondrial calcium-sensitive fluorescent probe Fura $6 \mathrm{~F}(250 \mathrm{nM})$. The mitochondrial suspensions were infused with $200 \mathrm{nmol} \mathrm{CaCl}_{2} / \mathrm{mg} / \mathrm{min}$ $(10 \mu \mathrm{M} / \mathrm{min})$.

\section{6-well plate assay for $\mathrm{H}_{2} \mathrm{O}_{2}$ production}

The cyclosporin analogs were tested in a 96well plate assay for inhibitory properties of calciuminduced $\mathrm{H}_{2} \mathrm{O}_{2}$ production. Experimental conditions were as described above for cuvette experiments except that they were run at room temperature and rat liver mitochondria were employed in this assay due to a considerably higher yield than brain mitochondria and could be used at $0.5 \mathrm{mg} / \mathrm{ml}$. Following calcium exposure (0.5 $\mu \mathrm{mol} / \mathrm{mg}$ mitochondrial protein), resorufin fluorescence was measured every $5 \mathrm{~min}$. Experiments included a vehicle control and a control of basal $\mathrm{H}_{2} \mathrm{O}_{2}$ production without calcium present.

\section{Mitochondrial respiration}

Mitochondrial oxygen consumption was measured in air-tight chambers using Clark-type oxygen electrodes. A first set of experiments were performed in equipment from Hansatech, Norfolk, UK, with $0.1 \mathrm{mg}$ mitochondria in $0.4 \mathrm{ml} \mathrm{KCl}$ buffer (see buffer composition above) at $30^{\circ} \mathrm{C}$. In order to evaluate respiratory changes following $\mathrm{mPT}$ in more detail, a second set of experiments were performed in a highresolution respirometer, Oroboros Oxygraph-2k, with high sensitivity, low noise and concentration-dependent background correction (Oroboros Instruments, Innsbruck, Austria). These experiments were run at $37^{\circ} \mathrm{C}$ with $0.1 \mathrm{mg}$ mitochondria in $2 \mathrm{ml} \mathrm{KCl}$ buffer and the $\mathrm{O}_{2}$ flux was monitored in real-time output using DatLab 4 software. For the multiple substrate/inhibitor protocol evaluating activity of respiratory complexes with or without presence of $800 \mu \mathrm{M} \mathrm{Ca}^{2+}$ (Fig. 5D) $10 \mu \mathrm{M} \mathrm{Cyt} \mathrm{c}$ and $1 \mathrm{mg} / \mathrm{ml} \mathrm{BSA} \mathrm{(Sigma} \mathrm{A8806)} \mathrm{were} \mathrm{present} \mathrm{in} \mathrm{the}$ 
buffer and mitochondria were permeabilized with 25 $\mu \mathrm{g} / \mathrm{ml}$ alamethicin.

\section{Measurement of cytochrome c (Cyt c) release and GSH content}

An ELISA kit for detection of rodent Cyt c (Quantikine ${ }^{\circledR}$ M, R\&D Systems, Abingdon, UK) was employed to measure Cyt c release. Mitochondrial samples were collected after experiments measuring light scattering and $\mathrm{H}_{2} \mathrm{O}_{2}$ production. Directly at the end of experiments, $1 \mathrm{mM}$ EGTA was added to prevent further $\mathrm{Ca}^{2+}$ insult. The samples were supplemented with a protease inhibitor cocktail (Sigma P-2714), rapidly chilled on ice and centrifuged at $7000 \mathrm{~g}$ for $10 \mathrm{~min}$. After a second centrifugation of the supernatant at $436000 \mathrm{~g}$ for $60 \mathrm{~min}$ the supernatants and pooled pellets were tested for Cyt c content. Total GSH content was determined using a Glutathione Colorimetric Detection Kit (ApoGSH ${ }^{\mathrm{TM}}$, BioVision, Mountain View, CA, USA), generating 2-Nitro-5-thiobenzoic acid from DTNB (5,5'Dithiobis(2-nitrobenzoic acid)) and GSH. GSH content was determined by measuring absorbance at $415 \mathrm{~nm}$.

\section{Electron microscopy}

Mitochondrial samples were prepared following incubation in buffers or following exposure to $1.4,8.0$ $\mu \mathrm{mol} \mathrm{Ca}{ }^{2+} / \mathrm{mg}$ mitochondria or $10 \mu \mathrm{g} / \mathrm{ml}$ alamethicin. The suspension was rapidly chilled and centrifuged in an Eppendorf microcentrifuge, $12000 \mathrm{~g}$, for $2 \mathrm{~min}$. Samples were fixed in a solution containing $0.1 \mathrm{M}$ Sörensen buffer, $1.5 \%$ Paraformaldehyde and $1.5 \%$ Glutaraldehyde over night, and further processed as described previously [30].

\section{Statistical analysis}

Data is presented as mean $\pm \mathrm{SD}$ and traces are representative for at least 3-4 separate experiments and analyzed using one-way ANOVA and the Bonferroni post hoc correction for multiple comparisons unless otherwise indicated. The level of statistical significance was set to $5 \%$.

\section{RESULTS}

Analysis of $\mathrm{H}_{2} \mathrm{O}_{2}$ generation following calcium-induced $m P T$ and unspecific permeabilization of the inner mitochondrial membrane

In respiring brain mitochondria the application of calcium will trigger a rapid permeability change of the inner membrane (mPT). The extent of swelling (commonly employed as an indirect measure of the change in permeability) in a defined population of mitochondria is dependent on the calcium dose and regulatory factors present within the mitochondria and the surrounding medium. Here calcium chloride was given as bolus administration in a dose resulting in near maximal swelling (i.e. near the light scattering decrease induced by the unspecific ionophore alamethicin) (Fig. 1B), and which could be fully prevented by the presence of the mPT inhibitor CsA in combination with ADP (and oligomycin) (Fig. 1B). The basal release of $\mathrm{H}_{2} \mathrm{O}_{2}$ from cortical brain and liver mitochondria oxidizing malate and glutamate was readily detected using the Amplex Red assay (exemplified for brain mitochondria in Fig. 1A) and the induction of mPT with $3.0 \mu \mathrm{mol} \mathrm{Ca}{ }^{2+} / \mathrm{mg}$ mitochondria caused an increase in the rate of $\mathrm{H}_{2} \mathrm{O}_{2}$ detection. Preventing $\mathrm{mPT}$ with a combination of CsA and $\mathrm{ADP}$ resulted in a decreased rate of $\mathrm{H}_{2} \mathrm{O}_{2}$ release following calcium addition (Fig. 1A, B). To validate our findings in rodent brain and liver mitochondria we exposed freshly isolated human liver mitochondria to a calcium insult (2.0-3.0 $\mu \mathrm{mol} \mathrm{Ca} \mathrm{Ca}^{2+} / \mathrm{mg}$ mitochondria) with and without CsA. Similar to the response of rodent mitochondria, inhibition of $\mathrm{mPT}$ prevented the calciuminduced increase in $\mathrm{H}_{2} \mathrm{O}_{2}$ production in human mitochondria (Fig. 1C).

The $\mathrm{H}_{2} \mathrm{O}_{2}$ detection was under all conditions highly sensitive to catalase ( $4000 \mathrm{U} / \mathrm{ml}$, data not shown). The basal generation of $\mathrm{H}_{2} \mathrm{O}_{2}$ without calcium addition was not influenced by cyclosporins (Cyclosporin $\mathrm{H}$, CsA and DEBIO-025 were tested) in rodent liver or brain mitochondria (data not shown).

Next, to evaluate the effect of calcium per se, and allow detailed study of the regulation of $\mathrm{H}_{2} \mathrm{O}_{2}$ generation in permeabilized brain mitochondria, alamethicin was utilized to permeabilize the inner mitochondrial membrane. In addition, both a lower and a higher dose calcium were used to induce $\mathrm{mPT}$. The two doses of calcium selected, 1.4 and $8.0 \mu \mathrm{mol} \mathrm{Ca}^{2+} / \mathrm{mg}$, induced an extensive and similar swelling response both in detected light scattering changes (not shown) and in gross morphological appearance (Fig. 2D). Similarly, the extent of membrane potential decrease did not significantly differ between groups (not shown) and the detected level of GSH in brain mitochondria oxidizing malate and glutamate was extensively and similarly decreased following both calcium and alamethicin exposure to a near zero level (below the detection limit of the assay which was $1 \mathrm{ng}$ total glutathione/well). The rate of $\mathrm{H}_{2} \mathrm{O}_{2}$ production in energized mitochondria (oxidizing malate and glutamate) increased the most by the higher dose of calcium $(8.0 \mu \mathrm{mol} / \mathrm{mg}$ mitochondria $)$ with a significant difference compared to the lower dose (1.4 $\mu \mathrm{mol} / \mathrm{mg}$ mitochondria) (Fig. 2A, B). Unspecific permeabilization with alamethicin (in the absence of added calcium) also induced a similar increase in $\mathrm{H}_{2} \mathrm{O}_{2}$ production (Fig. 2A, B). Mitochondria did not contain any measurable endogenous calcium following isolation as addition of $18 \mathrm{mM} \mathrm{Na}^{+}$did not trigger any release of $\mathrm{Ca}^{2+}$, and addition of extra EGTA or EGTA plus $\mathrm{Ca}^{2+}$ ionophore A23187 to the mitochondria prior to permeabilization did not influence the triggered increase in $\mathrm{H}_{2} \mathrm{O}_{2}$ generation by alamethicin (not shown). Other permeabilizing agents $(20 \mu \mathrm{M}$ mastoparan and $0.05 \%$ digitonin) similarly increased brain mitochondrial $\mathrm{H}_{2} \mathrm{O}_{2}$ generation, whereas merely uncoupling by protonophores (e.g $0.5 \mu \mathrm{M}$ CCCP) markedly decreased $\mathrm{H}_{2} \mathrm{O}_{2}$ generation (not shown). The NO scavengers PTIO and carboxyPTIO (both evaluated at $100 \mu \mathrm{M}$ ) induced a general quenching of resorufin fluorescence but displayed no 
specific effect on calcium-induced $\mathrm{H}_{2} \mathrm{O}_{2}$ generation in brain mitochondria (not shown).

To investigate the possible correlation between resulting ROS production and the loss of Cyt $\mathrm{c}$ following mitochondrial swelling, supernatants and pellets were collected and analyzed for Cyt c content following swelling induced by calcium and alamethicin in both $\mathrm{KCl}$ and sucrose-based buffers (Fig. 2C). The extent of Cyt $\mathrm{c}$ release did not correlate with the resulting rate of $\mathrm{H}_{2} \mathrm{O}_{2}$ production, with e.g. a very prominent $(>25 \%$ of total Cyt c) release in the alamethicin group compared to the high calcium dose $(<5 \%$ of total Cyt $\mathrm{c})$ in the $\mathrm{KCl}$ buffer, not translating into a higher ROS production (Fig. 2A, C).

The effect of different respiratory substrates and inhibitors on the rate of $\mathrm{H}_{2} \mathrm{O}_{2}$ generation in permeabilized brain mitochondria

To study the effect of available electron donors on $\mathrm{H}_{2} \mathrm{O}_{2}$ production in permeabilized brain mitochondria, mitochondria were incubated in $\mathrm{KCl}$ buffer in the absence of respiratory substrates. Mitochondria were permeabilized with alamethicin and not calcium, as the latter is dependent on mitochondrial membrane potential for its uptake, which could translate into differences in permeabilization of the inner membrane. Both complex I- and II-linked substrates, as well as $\mathrm{NADH}$, induced $\mathrm{H}_{2} \mathrm{O}_{2}$ generation under these conditions (Fig. 3, upper panel). In addition, the rate of $\mathrm{H}_{2} \mathrm{O}_{2}$ generation using complex I-linked substrates was enhanced when NADH or $\mathrm{NAD}^{+}$had previously been added. The oxidation of added NADH to mitochondria without other substrates was rapid and the increased rate of $\mathrm{H}_{2} \mathrm{O}_{2}$ production was maintained until NADH was fully oxidized (Fig. 3. compare trace 2 in upper panel with $\mathrm{NAD}(\mathrm{P}) \mathrm{H}$ fluorescence in the lower panel). The addition of malate and glutamate resulted in a more reduced state of $\mathrm{NAD}(\mathrm{P}) \mathrm{H}$. Importantly, the same dose $\mathrm{NADH}$ given to intact mitochondria or buffer without mitochondria did not trigger any increase in resorufin fluorescence (not shown).

The production of ROS is expected to increase with certain inhibitors of the respiratory chain complexes. In brain mitochondria oxidizing malate and glutamate the addition of the inhibitors rotenone (complex I) or antimycin A (complex III) caused large increases in the rate of $\mathrm{H}_{2} \mathrm{O}_{2}$ release in intact mitochondria. The increased ROS detection was further exacerbated by alamethicin permeabilization (Fig. 4). Permeabilization caused an immediate drop in $\mathrm{NAD}(\mathrm{P}) \mathrm{H}$ fluorescence both with and without rotenone present, but the oxidation of subsequently added NADH was inhibited by rotenone (Fig. 4, lower panel).

The addition of NADH to permeabilized mitochondria with respiratory inhibitors present induced both a larger relative and absolute increased rate of $\mathrm{H}_{2} \mathrm{O}_{2}$ generation than the effect without respiratory inhibition (Fig. 4, only shown for rotenone). Further, the rate of $\mathrm{H}_{2} \mathrm{O}_{2}$ production following addition of antimycin A to permeabilized mitochondria oxidizing malate and glutamate was doubled with a slightly increased NAD $(\mathrm{H})$ pool (continuation of experiments in Fig. 3, not shown).

Changes in mitochondrial oxygen consumption induced by $m P T$, calcium and unspecific permeabilization

Bovine serum albumin was generally omitted during isolation and experiments to avoid possible scavenging of ROS-related products and interference with the ROS detection assays. The respiratory control ratio (RCR) determined for cortical brain mitochondria oxidizing malate and glutamate under such conditions in ordinary low-resolution polarographic equipment (Clarktype electrodes) at $30^{\circ} \mathrm{C}$ was $4.24 \pm 0.60$. With BSA present during the isolation procedure, RCR was increased to $6.83 \pm 0.24$ and with BSA present also in the respiration buffer $(0.7 \mathrm{mg} / \mathrm{ml}) \mathrm{RCR}$ increased to $12.2 \pm$ 2.62. This substantial effect of BSA was mainly due to lowered resting respiratory rates with subsequent effects on the calculated RCR. In all cases the RCR was calculated with a state 4 without oligomycin present. The addition of calcium initially stimulated respiration, likely related to the loss of membrane potential during calcium uptake. This was followed by a substantial decline of oxygen consumption (Fig. 5A). Permeabilization with alamethicin immediately decreased the respiratory rate without initial stimulation. After the addition of either calcium or alamethicin, the mitochondria were fully uncoupled with no response to ADP application (Fig. $5 \mathrm{~A})$.

Using high-resolution respirometry we compared the influence of the selected calcium dosage (1.4 and $8.0 \mu \mathrm{mol} \mathrm{Ca}^{2+} / \mathrm{mg}$ mitochondria) and alamethicin on the oxygen consumption rates of brain mitochondria oxidizing malate and glutamate at $37{ }^{\circ} \mathrm{C}$ (Fig. 5B). Following the initial stimulation of respiration by calcium, there was a more rapid and pronounced inhibition by the higher calcium dose as compared to the lower. Alamethicin induced a further more extensive respiratory inhibition $(\mathrm{p}<0.05$ for all comparisons between the groups, Fig. 5C). Comparing the rates of respiration to rates of $\mathrm{H}_{2} \mathrm{O}_{2}$ detection, $0.15 \%$ of $\mathrm{O}_{2}$ was converted to $\mathrm{H}_{2} \mathrm{O}_{2}$ under resting state 2 respiration. Following permeabilization, a significantly larger part of consumed $\mathrm{O}_{2}$ was converted to $\mathrm{H}_{2} \mathrm{O}_{2}$ for both the lower and higher dose calcium as well as for alamethicin $(0.54 \%, 2.1 \%$ and $2.5 \%$, respectively, Fig. 5C).

A multiple substrate/inhibitor protocol was performed in mitochondria permeabilized by alamethicin in presence of $800 \mu \mathrm{M} \mathrm{Ca}^{2+}$ or vehicle in order to evaluate whether the respiration difference between the calcium doses was due to slightly different degrees of $\mathrm{mPT}$ induction or due to direct effects of calcium on the respiratory complexes (Fig. 5D). In permeabilized brain mitochondria without exogenously added substrates oxygen consumption was infinitesimal. However, administration of the usually impermeable NADH (200 $\mu \mathrm{M})$ to permeabilized mitochondria resulted in a very fast oxidation to $\mathrm{NAD}^{+}$and a high rate of oxygen consumption (Fig. 5D). In contrast, NADH displayed no significant effect on respiration in intact mitochondria 
(not shown). Addition of $5 \mathrm{mM}$ malate and glutamate to permeabilized mitochondria in presence of the supplemented $\mathrm{NAD}(\mathrm{H})$ resulted in several orders of magnitude higher respiration rate than the rate with only $5 \mathrm{mM}$ malate and glutamate and also several-fold higher rate than state 2 in intact mitochondria (compare rates in Fig. 5B and D). Following inhibition of complex I by rotenone, mitochondria were supplemented with succinate $(5 \mathrm{mM})$, and following inhibition of complex III by antimycin A, ascorbate and TMPD were supplied as substrates for cytochrome $\mathrm{c}$ oxidase. Calcium in itself exerted no significant effect on any of the respiratory rates in already permeabilized mitochondria.

Analysis of net $\mathrm{H}_{2} \mathrm{O}_{2}$ generation/scavenging in intact mitochondria versus mitochondria exposed to bolus dose or continuous infusion of calcium

In order to evaluate changes in mitochondrial $\mathrm{H}_{2} \mathrm{O}_{2}$ scavenging capacity, accumulation of $\mathrm{H}_{2} \mathrm{O}_{2}$ in mitochondrial suspensions were determined in experiments where the ROS detection reagents were not present from start, as the assay has a higher affinity for $\mathrm{H}_{2} \mathrm{O}_{2}$ than the endogenous mitochondrial scavenging pathways. The balance between mitochondrial generation and detoxification of $\mathrm{H}_{2} \mathrm{O}_{2}$ will therefore not be accurately reflected by the assay. Mitochondria exposed to a calcium bolus load followed by antimycin A demonstrated an accumulation of $\mathrm{H}_{2} \mathrm{O}_{2}$ in the suspending buffer, which was readily detected by a delayed administration of the $\mathrm{H}_{2} \mathrm{O}_{2}$ reagents (Fig. 6A). HRP and Amplex Red added $7 \mathrm{~min}$ after calcium or at start of experiments resulted in closely paralleled fluorescence levels (Fig. 6A, trace 1 and 3) indicating that under these conditions, there was no significant mitochondrial scavenging of $\mathrm{H}_{2} \mathrm{O}_{2}$. In contrast, when mitochondria which had not undergone calcium-induced $\mathrm{mPT}$ were exposed to antimycin A, there was no evident accumulation of $\mathrm{H}_{2} \mathrm{O}_{2}$. Delayed administration of HRP and Amplex Red in these structurally intact mitochondria resulted in a similar rate of $\mathrm{H}_{2} \mathrm{O}_{2}$ generation as when the reagents were present from start, but importantly, the fluorescence signal started at a near zero level (Fig. 6A, trace 1 and 4). This demonstrates that all generated $\mathrm{H}_{2} \mathrm{O}_{2}$ was detoxified by mitochondria in the absence of the ROS assay reagents. In an additional experiment, mitochondria were exposed to a slow continuous infusion of calcium rather than a sudden bolus load, and extramitochondrial $\left[\mathrm{Ca}^{2+}\right]$ was monitored (Fig. 6B). The infused calcium was taken up by mitochondria incubated with $200 \mu \mathrm{M}$ ADP to a certain amount when the retained calcium was suddenly released (trace 5). In mitochondria incubated with $1 \mathrm{mM}$ ADP and $1 \mu \mathrm{M} \mathrm{CsA}$, all the infused calcium was retained (trace 6). Experiments were continued with administration of antimycin A and after 6 min HRP and Amplex Red. Mitochondria which had undergone a calcium deregulation (mPT) demonstrated a net accumulation of $\mathrm{H}_{2} \mathrm{O}_{2}$ in the surrounding buffer wheras mitochondria which had retained all calcium did not.
Correlation of $\mathrm{mPT}$ inhibitory properties with inhibition of calcium-induced $\mathrm{H}_{2} \mathrm{O}_{2}$ generation in a library of cyclosporin analogs

Using a 96-well plate system and the Amplex Red assay we investigated calcium-induced $\mathrm{H}_{2} \mathrm{O}_{2}$ release in the presence of $\mathrm{CsA}$ and 21 of its natural and semisynthetic analogs. Initially, the ability to inhibit calcium-induced mPT was determined in the deenergized assay and here we found a strong correlation $\left(\mathrm{R}^{2}=0.90, \mathrm{p}<0.0001\right)$ between $\mathrm{mPT}$ inhibition in mouse cortical brain and mouse liver mitochondria (not shown). In the 96-well plate screening study the ability of the analogs to prevent calcium-induced $\mathrm{H}_{2} \mathrm{O}_{2}$ generation in liver mitochondria correlated $\left(\mathrm{R}^{2}=0.83, \mathrm{p}<0.0001\right)$ to the ability to inhibit calcium-induced mPT (Fig. 7B, the identity of the different analogs is provided in Table 1). To illustrate this point, $\mathrm{H}_{2} \mathrm{O}_{2}$ detection following calcium application is depicted for two cyclosporin analogs, cyclosporin $\mathrm{C}$ (a potent $\mathrm{mPT}$ inhibitor) and cyclosporin $\mathrm{H}$ (a poor $\mathrm{mPT}$ inhibitor) together with vehicle (ethanol) and a control run without added calcium (Fig. 7A).

\section{DISCUSSION}

The main and novel findings of the present study are firstly that brain-derived mitochondria as well as human liver mitochondria display a sustained and even increased production of ROS following calciuminduced $\mathrm{mPT}$, as detected by Amplex Red, even though their respiration is severely inhibited and membrane potential as well as NADH are lost, conditions normally associated with pronounced reduction in ROS generation $[31,32]$. Secondly, as a plausible explanation to this apparent contradiction, we demonstrate that the ability of brain mitochondria to detoxify $\mathrm{H}_{2} \mathrm{O}_{2}$ was virtually eliminated following $\mathrm{mPT}$ and that this loss of antioxidant function translated into a considerable net release and extramitochondrial accumulation of $\mathrm{H}_{2} \mathrm{O}_{2}$. Importantly, the triggered $\mathrm{H}_{2} \mathrm{O}_{2}$ release was related to these bioenergetic consequences of $\mathrm{mPT}$ on the antioxidant function and not by calcium effects per se. The degree of ROS generation was dependent on the availability of respiratory substrates and even a low concentration of supplemented $\mathrm{NAD}(\mathrm{H})$ considerably increased ROS production in permeabilized mitochondria. Finally, the calcium-induced ROS generation in brain and liver mitochondria was inhibited by cyclosporin $\mathrm{A}$ and 21 cyclosporin analogs in a manner strongly correlating to their potency of inhibiting calcium-induced mitochondrial swelling (mPT).

Some of the parameters that are highly associated with pronounced ROS production in intact (brain) mitochondria, most notably a high membrane potential and $\mathrm{NADH}$ in its reduced form [33], are dramatically diminished in mitochondria that have undergone $\mathrm{mPT}$. In combination with an $\mathrm{mPT}$-induced loss of respiratory substrates to the extramitochondrial space, these physiological alterations would be expected to decrease ROS production. The net increase in ROS as demonstrated in the present work could plausibly be 
related to several other factors influencing ROS generation. First, the release of Cyt $\mathrm{c}$ that may follow an $\mathrm{mPT}$ due to swelling of mitochondria with disruption of the outer membrane can increase ROS by causing a reduced shift of the ETC and by loss of its superoxide scavenging function $[6,34]$. However, the Cyt c release of brain mitochondria in the present study did not correlate to the extent of ROS increase.

Secondly, calcium displays several actions that at least theoretically could increase ROS generation from mitochondria. Among them are the regulatory role effect of calcium on several dehydrogenases (although primary substrates for these were not used in the present study), activation of nitric oxide synthase, lipid rearrangements and structural alterations of respiratory complexes as well as inhibition of antioxidative pathways [35-39]. It is important to bear in mind that even though mitochondria can accumulate large amounts of calcium under normal physiological conditions, inactive calcium-phosphates are formed in the alkaline matrix keeping free calcium ions in the low micromolar range [23]. In the present study the stimulatory effect of calcium on ROS generation was tightly coupled to whether it triggers $\mathrm{mPT}$ or not. Mitochondria exposed to calcium in presence of sufficient $\mathrm{mPT}$ inhibitors demonstrated no increase in $\mathrm{H}_{2} \mathrm{O}_{2}$ generation (Fig. 1) and retained the ability to detoxify $\mathrm{H}_{2} \mathrm{O}_{2}$ (Fig. 6B). Differences in the proportion and extent of the mitochondrial population undergoing permeability changes, as detected by highresolution respirometry, likely accounted for the higher magnitude of $\mathrm{H}_{2} \mathrm{O}_{2}$ increase by the higher dose calcium in Fig. 2. Scavengers of nitric oxide did not prevent calcium-induced $\mathrm{H}_{2} \mathrm{O}_{2}$ generation, and a high concentration of calcium in permeabilized mitochondria, $800 \mu \mathrm{M}$ in Fig. 5D compared to the normal low micromolar concentrations in intact mitochondria, did not alter respiratory activities in the multiple substrate/inhibitor protocol performed using highresolution respirometry.

Finally, reduced glutathione and NADPH provide antioxidant defenses against $\mathrm{H}_{2} \mathrm{O}_{2}$ mediated damage through the action of e.g. the glutathione peroxidase family, peroxiredoxins and glutaredoxins. The most well studied enzyme glutathione peroxidase (GPx1) oxidizes glutathione to glutathione disulfide and converts $\mathrm{H}_{2} \mathrm{O}_{2}$ to water [1]. Glutathione disulfide is reduced via glutathione reductase in an NADPHconsuming process, and hence the redox status of $\mathrm{NADP}(\mathrm{H})$ determines the redox status of the glutathione pool. In the mitochondrial matrix, NADPH is held highly reduced by the $\Delta \mathrm{p}$-driven energy-linked nicotinamide nucleotide transhydrogenase but can also be generated by malic enzyme and isocitrate dehydrogenase [3]. Upon $\mathrm{mPT}$, the protonmotive force $(\Delta \mathrm{p})$ and reduced $\mathrm{NAD}(\mathrm{P}) \mathrm{H}$ are lost and consequently also the reducing requirements for glutathione. An increased detection of $\mathrm{H}_{2} \mathrm{O}_{2}$ following calcium-induced mPT may therefore not be caused by an increased production of $\mathrm{H}_{2} \mathrm{O}_{2}$ per se, rather by an abolished endogenous detoxification.
The present study suggests that the bioenergetic consequence of $\mathrm{mPT}$, leading to loss of antioxidant ROS detoxification, may be the most important factor causing increased ROS following calcium-induced $\mathrm{mPT}$. Mitochondria are commonly referred to as the most significant source of ROS in the cell. Yet, brain mitochondria have been reported to be capable of a high rate of exogenous $\mathrm{H}_{2} \mathrm{O}_{2}$ removal, far exceeding the reported production rates [39] and when ROS was measured in supernatants separated from normal intact mitochondria without respiratory inhibitors no accumulated ROS was detected [40], in accordance with our studies. This calls attention to the question whether mitochondria act as a net sink or a net source of ROS and warrants detailed study of conditions where this balance may shift.

As elegantly demonstrated by Andreyev et al., in an effort to probe the balance of ROS production and removal, net production with extramitochondrial accumulation of ROS requires structurally compromised mitochondria, and further, the net balance can not be appreciated if the ROS-reacting enzymes (in the ROS assay) are competing with the endogenous detoxifying systems during the experiment [41]. We demonstrate that mPT induced by a bolus load or a continuous infusion of calcium (but not mitochondrial calcium accumulation per $s e$ in the absence of $\mathrm{mPT}$ ) induces such compromised mitochondria with a net accumulation of ROS. Thus, whereas intact mitochondria, at least in an isolated state, can serve as a net sink rather than a net source of ROS, mitochondria with disrupted antioxidative pathways subsequent to $\mathrm{mPT}$ may truly act as a net source of ROS.

Further, in the present work, the ROS increase following permeabilization of mitochondria was more pronounced if suspensions were supplemented with a low concentration $(1.5 \mu \mathrm{M})$ of $\mathrm{NAD}^{+}$or $\mathrm{NADH}$, i.e. a concentration well below expected intracellular $\operatorname{NAD}(\mathrm{H})$ levels in view of reported total brain tissue $\mathrm{NAD}(\mathrm{H})$ concentrations, 250-300 $\mu \mathrm{mol} / \mathrm{kg}$ [42]. Very high respiration rates could also be achieved in permeabilized mitochondria by direct addition of NADH or using NADH-linked substrates with an increased $\mathrm{NAD}^{+}$pool demonstrating a retained and substantial electron flow capability through the ETC when regulation of respiration by the protonmotive force is lost. Thus, depending on the availability of respiratory substrates in vivo, the rate of net ROS generation from mitochondria following $\mathrm{mPT}$ may be substantially higher compared to the in vitro conditions where the mitochondrial $\mathrm{NADH}$ content is extensively diluted. Consequently, ROS as a result of $\mathrm{mPT}$, in a larger or smaller proportion of the mitochondria in a cell, may provide significant contribution to the cell death pathways adding to perturbations caused by $\mathrm{mPT}$-induced restriction of ATP production and release of proapoptotic proteins from mitochondria.

Several studies have coupled excitotoxic neuronal degeneration to mitochondrial calcium loading and ROS production. Delayed calcium deregulation (DCD) of mitochondria in models of glutamate toxicity 
has been demonstrated to be a committal step towards cell death. A classical view is that calcium-loaded mitochondria generate ROS, which trigger DCD and cell death $[10,11]$. However, it is not settled if oxidative stress precedes the DCD and is a causative factor or if it is a consequence of DCD $[15,16]$. Assuming that DCD is synonymous with calcium-induced $\mathrm{mPT}$ (which is controversial), our results favor the latter interpretation. Single cell analysis of cerebellar granule neurons has demonstrated a significant increase in superoxide only upon induction of DCD, and cell permeable antioxidants were not able to delay DCD [14]. A combination of antioxidants in hippocampal neurons similarly did not prevent mitochondrial depolarization or DCD but despite this conferred significant protection of cell viability [13]. Limiting the ROS-mediated damage by antioxidants is thus one potential pharmacological target and mPTinhibition another, although the pathways may intertwine due to ROS-induced ROS release [43]. Glutamate excitotoxicity is one of several pathogenic processes in neurodegeneration and $\mathrm{mPT}$ is likely one mechanism of glutamate-induced cell death. CsA is generally employed to evaluate $\mathrm{mPT}$ involvement in cell death pathways. CsA is however not specific for mPT since it also inhibits calcineurin (unlike the non-immunosuppressive analogs tested in the present study) and nonmitochondrial cyclophilins, and CsA has not consistently provided cytoprotection in cellular models of glutamate excitotoxicity [44]. CsA and its non-immunosuppressive analogs have however more robustly mediated neuroprotection in animal models of global and focal cerebral ischemia, traumatic brain injury and amyotrophic lateral sclerosis when means are taken to deliver the drug to the central nervous system [25, 45]. More specific evidence for the involvement of $\mathrm{mPT}$ in neurological disorders has more recently been obtained with genetically modified mice lacking cyclophilin D, an important modulator of the $\mathrm{mPT}$ and the mitochondrial receptor for CsA. The knock-out mediated resistance to cerebral focal ischemia, experimental multiple sclerosis and as well cardiac ischemia [46-48].

We propose, based on the present findings in isolated mitochondria, that $\mathrm{mPT}$ is the mechanism linking mitochondrial calcium uptake with pathological ROS generation in excitotoxic cell death and in the burst of ROS production seen in the reperfusion phase of ischemia-reperfusion. Therefore, pharmacological agents aimed at preventing $\mathrm{mPT}$ and the resulting oxidative stress can potentially dampen the cellular perturbations and promote neuronal survival under these pathological conditions.

\section{Acknowledgments}

This study was supported by the Swedish Research Council (Project No. 08644), by the Japanese Ministry of Health, Labour and Welfare Grant No. 18591724, the Swedish Society of Medicine and the foundations of Laerdal, Åhlén, Stohne, Segerfalk and the Royal Physiographic Society in Lund. The authors are grateful to Hans Friberg and Gustav Mattiasson for inspiration and methodological input and to Tadeusz Wieloch and Olle Lindvall for support. Commercial bindings: author EE and MFK are founders of Maas BiolAB, LLC and NeuroVive Pharmaceutical AB, which hold intellectual property rights and develop the use of cyclosporins for neurological treatment.

\section{REFERENCES}

[1] Droge, W. Free radicals in the physiological control of cell function. Physiol Rev 82:47-95; 2002.

[2] Beal, M. F. Mitochondria, free radicals, and neurodegeneration. Curr Opin Neurobiol 6:661$666 ; 1996$.

[3] Nicholls, D. G.; Budd, S. L. Mitochondria and neuronal survival. Physiol Rev 80:315-360; 2000.

[4] Das, D. K.; Maulik, N.; Sato, M.; Ray, P. S. Reactive oxygen species function as second messenger during ischemic preconditioning of heart. Mol Cell Biochem 196:59-67; 1999.

[5] Gutierrez, J.; Ballinger, S. W.; Darley-Usmar, V. M.; Landar, A. Free radicals, mitochondria, and oxidized lipids: the emerging role in signal transduction in vascular cells. Circ Res 99:924932; 2006.

[6] Turrens, J. F. Mitochondrial formation of reactive oxygen species. J Physiol 552:335-344; 2003.

[7] Lipton, P. Ischemic cell death in brain neurons. Physiol Rev 79:1431-1568; 1999.

[8] Salinska, E.; Danysz, W.; Lazarewicz, J. W. The role of excitotoxicity in neurodegeneration. Folia Neuropathol 43:322-339; 2005.

[9] Rego, A. C.; Oliveira, C. R. Mitochondrial dysfunction and reactive oxygen species in excitotoxicity and apoptosis: implications for the pathogenesis of neurodegenerative diseases. Neurochem Res 28:1563-1574; 2003.

[10] Reynolds, I. J.; Hastings, T. G. Glutamate induces the production of reactive oxygen species in cultured forebrain neurons following NMDA receptor activation. $J$ Neurosci 15:3318-3327; 1995.

[11] Dugan, L. L.; Sensi, S. L.; Canzoniero, L. M.; Handran, S. D.; Rothman, S. M.; Lin, T. S.; Goldberg, M. P.; Choi, D. W. Mitochondrial production of reactive oxygen species in cortical neurons following exposure to N-methyl-Daspartate. J Neurosci 15:6377-6388; 1995.

[12] Sengpiel, B.; Preis, E.; Krieglstein, J.; Prehn, J. H. NMDA-induced superoxide production and neurotoxicity in cultured rat hippocampal neurons: role of mitochondria. Eur J Neurosci 10:1903$1910 ; 1998$.

[13] Vergun, O.; Sobolevsky, A. I.; Yelshansky, M. V.; Keelan, J.; Khodorov, B. I.; Duchen, M. R. Exploration of the role of reactive oxygen species in glutamate neurotoxicity in rat hippocampal neurones in culture. J Physiol 531:147-163; 2001.

[14] Vesce, S.; Kirk, L.; Nicholls, D. G. Relationships between superoxide levels and delayed calcium deregulation in cultured cerebellar granule cells 
exposed continuously to glutamate. $J$ Neurochem 90:683-693; 2004.

[15] Duan, Y.; Gross, R. A.; Sheu, S. S. Ca2+dependent generation of mitochondrial reactive oxygen species serves as a signal for poly(ADPribose) polymerase-1 activation during glutamate excitotoxicity. J Physiol 585:741-758; 2007.

[16] Nicholls, D. G. Mitochondrial dysfunction and glutamate excitotoxicity studied in primary neuronal cultures. Curr Mol Med 4:149-177; 2004.

[17] Starkov, A. A.; Chinopoulos, C.; Fiskum, G. Mitochondrial calcium and oxidative stress as mediators of ischemic brain injury. Cell Calcium 36:257-264; 2004.

[18] Maciel, E. N.; Vercesi, A. E.; Castilho, R. F. Oxidative stress in $\mathrm{Ca}(2+)$-induced membrane permeability transition in brain mitochondria. $J$ Neurochem 79:1237-1245; 2001.

[19] Brustovetsky, N.; Brustovetsky, T.; Purl, K. J.; Capano, M.; Crompton, M.; Dubinsky, J. M. Increased susceptibility of striatal mitochondria to calcium-induced permeability transition. J Neurosci 23:4858-4867.; 2003.

[20] Panov, A.; Dikalov, S.; Shalbuyeva, N.; Hemendinger, R.; Greenamyre, J. T.; Rosenfeld, J. Species- and tissue-specific relationships between mitochondrial permeability transition and generation of ROS in brain and liver mitochondria of rats and mice. Am $J$ Physiol Cell Physiol 292:C708-718; 2007.

[21] Votyakova, T. V.; Reynolds, I. J. Ca2+-induced permeabilization promotes free radical release from rat brain mitochondria with partially inhibited complex I. J Neurochem 93:526-537; 2005.

[22] Schönfeld, P.; Reiser, G. Ca2+ storage capacity of rat brain mitochondria declines during the postnatal development without change in ROS production capacity. Antioxid Redox Signal 9:191-199; 2007.

[23] Nicholls, D. G. Mitochondria and calcium signaling. Cell Calcium 38:311-317; 2005.

[24] Crompton, M. The mitochondrial permeability transition pore and its role in cell death. Biochem $J$ 341:233-249; 1999.

[25] Wieloch, T.; Mattiasson, G.; Hansson, M. J.; Elmér, E. Mitochondrial Permeability Transition in the CNS-Composition, Regulation, and Pathophysiological Relevance. In: Lajtha, A.; Gibson, G. E.; Dienel, G. A., eds. Handbook of Neurochemistry and Molecular Neurobiology Brain Energetics. Integration of Molecular and Cellular Processes: Springer, New York, NY, USA; 2007: 667-702.

[26] Sims, N. Rapid isolation of metabolically active mitochondria from rat brain and subregions using percoll density gradient centrifugation. $J$ Neurochem 55:698-707; 1990.

[27] Hansson, M. J.; Persson, T.; Friberg, H.; Keep, M. F.; Rees, A.; Wieloch, T.; Elmér, E. Powerful cyclosporin inhibition of calcium-induced permeability transition in brain mitochondria. Brain Res 960:99-111; 2003.

[28] Hansson, M. J.; Mattiasson, G.; Mansson, R.; Karlsson, J.; Keep, M. F.; Waldmeier, P.; Ruegg, U. T.; Dumont, J. M.; Besseghir, K.; Elmer, E. The nonimmunosuppressive cyclosporin analogs NIM811 and UNIL025 display nanomolar potencies on permeability transition in brainderived mitochondria. $J$ Bioenerg Biomembr 36:407-413; 2004.

[29] Votyakova, T. V.; Reynolds, I. J. Detection of hydrogen peroxide with Amplex Red: interference by NADH and reduced glutathione auto-oxidation. Arch Biochem Biophys 431:138-144; 2004.

[30] Morota, S.; Hansson, M. J.; Ishii, N.; Kudo, Y.; Elmér, E.; Uchino, H. Spinal cord mitochondria display lower calcium retention capacity compared with brain mitochondria without inherent differences in sensitivity to cyclophilin D inhibition. J Neurochem 103:2066-2076; 2007.

[31] Korshunov, S. S.; Skulachev, V. P.; Starkov, A. A. High protonic potential actuates a mechanism of production of reactive oxygen species in mitochondria. FEBS Lett 416:15-18; 1997.

[32] Hansford, R. G.; Hogue, B. A.; Mildaziene, V. Dependence of $\mathrm{H} 2 \mathrm{O} 2$ formation by rat heart mitochondria on substrate availability and donor age. J Bioenerg Biomembr 29:89-95; 1997.

[33] Starkov, A. A.; Fiskum, G. Regulation of brain mitochondrial $\mathrm{H} 2 \mathrm{O} 2$ production by membrane potential and NAD(P)H redox state. $J$ Neurochem 86:1101-1107; 2003.

[34] Korshunov, S. S.; Krasnikov, B. F.; Pereverzev, M. O.; Skulachev, V. P. The antioxidant functions of cytochrome c. FEBS Lett 462:192-198; 1999.

[35] Soane, L.; Solenski, N.; Fiskum, G. Mitochondrial Mechanisms of Oxidative Stress and Apoptosis. In: Lajtha, A.; Gibson, G. E.; Dienel, G. A., eds. Handbook of Neurochemistry and Molecular Neurobiology - Brain Energetics. Integration of Molecular and Cellular Processes: Springer, New York, NY, USA; 2007: 703-734.

[36] Orrenius, S.; Zhivotovsky, B.; Nicotera, P. Regulation of cell death: the calcium-apoptosis link. Nat Rev Mol Cell Biol 4:552-565; 2003.

[37] Grijalba, M. T.; Vercesi, A. E.; Schreier, S. Ca2+induced increased lipid packing and domain formation in submitochondrial particles. A possible early step in the mechanism of $\mathrm{Ca} 2+$-stimulated generation of reactive oxygen species by the respiratory chain. Biochemistry 38:13279-13287; 1999.

[38] Wikstrom, M.; Saari, H. A spectral shift in cytochrome a induced by calcium ions. Biochim Biophys Acta 408:170-179; 1975.

[39] Zoccarato, F.; Cavallini, L.; Alexandre, A. Respiration-dependent removal of exogenous $\mathrm{H} 2 \mathrm{O} 2$ in brain mitochondria: inhibition by $\mathrm{Ca} 2+. J$ Biol Chem 279:4166-4174; 2004. 
[40] Nohl, H.; Kozlov, A. V.; Gille, L.; Staniek, K. Cell respiration and formation of reactive oxygen species: facts and artefacts. Biochem Soc Trans 31:1308-1311; 2003.

[41] Andreyev, A. Y.; Kushnareva, Y. E.; Starkov, A. A. Mitochondrial metabolism of reactive oxygen species. Biochemistry (Mosc) 70:200-214; 2005.

[42] Klaidman, L. K.; Leung, A. C.; Adams, J. D., Jr. High-performance liquid chromatography analysis of oxidized and reduced pyridine dinucleotides in specific brain regions. Anal Biochem 228:312-317; 1995.

[43] Zorov, D. B.; Filburn, C. R.; Klotz, L. O.; Zweier, J. L.; Sollott, S. J. Reactive oxygen species (ROS)induced ROS release: a new phenomenon accompanying induction of the mitochondrial permeability transition in cardiac myocytes. $J$ Exp Med 192:1001-1014; 2000.

[44] Duchen, M. R. Mitochondria and calcium: from cell signalling to cell death. J Physiol 529 Pt 1:57$68 ; 2000$.

[45] Waldmeier, P. C.; Zimmermann, K.; Qian, T.; Tintelnot-Blomley, M.; Lemasters, J. J. Cyclophilin $\mathrm{D}$ as a drug target. Curr Med Chem 10:1485-1506.; 2003.

[46] Schinzel, A. C.; Takeuchi, O.; Huang, Z.; Fisher, J. K.; Zhou, Z.; Rubens, J.; Hetz, C.; Danial, N. N.; Moskowitz, M. A.; Korsmeyer, S. J. Cyclophilin D is a component of mitochondrial permeability transition and mediates neuronal cell death after focal cerebral ischemia. Proc Natl Acad Sci U S A 102:12005-12010; 2005.

[47] Forte, M.; Gold, B. G.; Marracci, G.; Chaudhary, P.; Basso, E.; Johnsen, D.; Yu, X.; Fowlkes, J.; Bernardi, P.; Bourdette, D. Cyclophilin D inactivation protects axons in experimental autoimmune encephalomyelitis, an animal model of multiple sclerosis. Proc Natl Acad Sci U S A 104:7558-7563; 2007.

[48] Baines, C. P.; Kaiser, R. A.; Purcell, N. H.; Blair, N. S.; Osinska, H.; Hambleton, M. A.; Brunskill, E. W.; Sayen, M. R.; Gottlieb, R. A.; Dorn, G. W.; Robbins, J.; Molkentin, J. D. Loss of cyclophilin D reveals a critical role for mitochondrial permeability transition in cell death. Nature 434:658-662; 2005.

[49] Jegorov, A.; Havlicek, V. Spontaneous N --> O acyl shift in the $[\mathrm{M}+\mathrm{H}](+)$ ions of [MeBmt1]cyclosporins in an ion trap. $J$ Mass Spectrom 36:633-640; 2001.

[50] Traber, R.; Kuhn, M.; Loosli, H. R.; Pache, W.; von Wartburg, A. [New cyclopeptides from Trichoderma polysporum (Link ex Pers.) Rifai: cyclosporins B, D and E (author's transl)]. Helvetica chimica acta 60:1568-1578; 1977. 
Table 1

Cyclosporin analogs grouped according to relative potency in inhibiting mitochondrial permeability transition (mPT)

Potent mPT-inhibitors (significant inhibition of $\mathrm{Ca}^{2+}$-induced swelling at $25 \mathrm{nM}$ )

\begin{tabular}{l|l|l}
\hline Cyclosporin analog (name and chemical modification) & $\#^{\mathbf{a}}$ & $\mathbf{M W}^{\mathbf{b}}$ \\
\hline Cyclosporin $\mathrm{A}=\mathrm{CS}=$ native cyclosporin $^{\mathrm{c}}$ & 20 & 1202.6 \\
$\mathrm{UNIL} 025=\left[\mathrm{MeAla}^{3} \mathrm{EtVal}{ }^{4}\right] \mathrm{CS}$ & 21 & 1216.6 \\
$\mathrm{NIM} 811=[\mathrm{MeIle}] \mathrm{CS}$ & 22 & 1202.6 \\
$\begin{array}{l}\text { Dihydro-cyclosporin A } \\
{\left[3 \text {-Hydroxy-4-methyl-2-methylamino-octanoic acid }{ }^{1}\right] \mathrm{CS}}\end{array}$ & 1 & 1204.6 \\
Cyclosporin $\mathrm{C}=\left[\mathrm{Thr}^{2}\right] \mathrm{CS}$ & 6 & 1218.6 \\
Cyclosporin $\mathrm{B}=\left[\mathrm{Ala}^{2}\right] \mathrm{CS}$ & 5 & 1188.6 \\
Cyclosporin $\mathrm{D}=\left[\mathrm{Val}^{2}\right] \mathrm{CS}$ & 7 & 1216.6 \\
Cyclosporin 3-oxo-D $=\left[4-\mathrm{Methyl}-2\right.$-methylamino-3-oxo-oct-6-enoic acid $\left.{ }^{1}, \mathrm{Val}^{2}\right] \mathrm{CS}$ & 8 & 1214.6 \\
Cyclosporin $\mathrm{G}=\left[\mathrm{Nva}^{2}\right] \mathrm{CS}$ & 11 & 1216.6 \\
\hline
\end{tabular}

Intermediate $\mathrm{mPT}$-inhibitors (significant inhibition of $\mathrm{Ca}^{2+}$-induced swelling at $1 \mu \mathrm{M}$ )

\begin{tabular}{|c|c|c|}
\hline Iso-cyclosporin $A=$ see ref [49] & 2 & 1202.6 \\
\hline $\begin{array}{l}\text { Trifluoroacetyl-cyclosporin A = [4-Methyl-2-methylamino-3-(2,2,2-trifluoro-acetoxy)-oct-6- } \\
\left.\text { enoic acid }{ }^{1}\right] C S\end{array}$ & 19 & 1298.6 \\
\hline Cyclosporin A [7-I-THF-MeBmt] = see ref [50] & 18 & 1328.5 \\
\hline Cyclosporin F = [4-Methyl-2-methylamino-oct-6-enoic acid $\left.{ }^{1}\right] C S$ & 10 & 1186.6 \\
\hline Cyclosporin $\mathrm{U}=\left[\mathrm{Leu}^{6}\right] \mathrm{CS}$ & 15 & 1188.6 \\
\hline Cyclosporin A sulphate $=\left[4-\right.$ Methyl-2-methylamino-3-sulfooxy-oct-6-enoic acid $\left.^{1}\right] C S$ & 16 & 1282.7 \\
\hline
\end{tabular}

Poor mPT-inhibitors (no significant inhibition of $\mathrm{Ca}^{2+}$-induced swelling at $1 \mu \mathrm{M}$ )

\begin{tabular}{|c|c|c|}
\hline Cyclosporin $\mathrm{Leu}^{4}=\left[\mathrm{Leu}^{4}\right] \mathrm{CS}$ & 14 & 1188.6 \\
\hline Cyclosporin $\mathrm{E}=\left[\mathrm{Val}^{11}\right] \mathrm{CS}$ & 9 & 1188.6 \\
\hline Cyclosporin $\mathrm{A}\left[-\mathrm{H}_{2} \mathrm{O}\right]=\left[4-\right.$ Methyl-2-methylamino-octa-3,6-dienoic acid $\left.{ }^{1}\right] \mathrm{CS}$ & 13 & 1184.6 \\
\hline Acetyl-cyclosporin $\mathrm{A}=\left[3\right.$-Acetoxy-4-methyl-2-methylamino-oct-6-enoic acid $\left.{ }^{1}\right] \mathrm{CS}$ & 4 & 1244.7 \\
\hline Cyclosporin A 3-oxo = [4-Methyl-2-methylamino-3-oxo-oct-6-enoic acid $\left.{ }^{1}\right] \mathrm{CS}$ & 17 & 1200.6 \\
\hline Cyclosporin $\mathrm{H}=\left[\mathrm{D}-\mathrm{MeVal}^{11}\right] \mathrm{CS}$ & 12 & 1202.6 \\
\hline Cyclosporin A [7-Br-THF-MeBmt $\left.{ }^{1}\right]=$ see ref $[50]$ & 3 & 1281.5 \\
\hline
\end{tabular}

\footnotetext{
${ }^{\mathrm{a}}$ Numbers correspond to those in Fig. 7.

${ }^{\mathrm{b}}$ Molecular weight (Da).

${ }^{\mathrm{c}}$ Native cyclosporin $=$ cyclo $\left(-\mathrm{Mebmt}^{1}-\mathrm{Abu}^{2}-\mathrm{Sar}^{3}-\mathrm{MeLeu}^{4}-\mathrm{Val}^{5}-\mathrm{MeLeu}^{6}-\mathrm{Ala}^{7}-\mathrm{D}-\mathrm{Ala}^{8}-\mathrm{MeLeu}^{9}-\mathrm{MeLeu}^{10}-\mathrm{MeVal}^{11}-\right)$, where MeBmt is (2S,3R,4R,6E)-2-methylamino-3-hydroxy-4-methyl-6-octenoic acid. The superscript in square brackets refers to the amino acid position where the change occurs with respect to cyclosporin $\mathrm{A}$.
} 


\section{Figure 1}

\section{FIGURE LEGENDS}

$\mathrm{H}_{2} \mathrm{O}_{2}$ generation of rat brain and human liver mitochondria exposed to calcium with or without inhibition of permeability transition (mPT). (A) Representative traces of mitochondrial $\mathrm{H}_{2} \mathrm{O}_{2}$ release as measured by Amplex Red oxidation to resorufin, and (B) calculations of $\mathrm{H}_{2} \mathrm{O}_{2}$ release rate and swelling of rat brain mitochondria. Mitochondria were suspended in sucrose-based buffer containing $5 \mathrm{mM}$ malate and glutamate as respiratory substrates and exposed to $3.0 \mu \mathrm{mol}$ $\mathrm{Ca}^{2+} / \mathrm{mg}(300 \mu \mathrm{M})$ in presence of $1 \mu \mathrm{M} \mathrm{CsA}, 0.5 \mathrm{mM}$ ADP and $1 \mu \mathrm{g} / \mathrm{ml}$ of the ATP synthase inhibitor oligomycin (trace 3 ) or vehicle (ethanol, trace 1). Controls were run without exposure to calcium (trace 2) but with oligomycin present. The proportion of mitochondria undergoing swelling was calculated by determining the extent of light scattering decrease compared to a standardized maximal decrease induced by the ionophore alamethicin $(10 \mu \mathrm{g} / \mathrm{ml})$ for each run. * and \# indicate significant difference compared to control for $\mathrm{H}_{2} \mathrm{O}_{2}$ and swelling measurements, respectively. (C) Representative traces of $\mathrm{H}_{2} \mathrm{O}_{2}$ release by liver mitochondria isolated from freshly resected human samples were run similarly, except that mitochondria were suspended in KCl-based buffer and CsA was used as the only permeability transition inhibitor.

\section{Figure 2}

$\mathrm{H}_{2} \mathrm{O}_{2}$ release, cytochrome $c$ release and electron micrographs of rat brain mitochondria undergoing permeability transition by different doses of calcium or by alamethicin permeabilization. Mitochondria were suspended in $\mathrm{KCl}-$ or sucrose-based buffer with $5 \mathrm{mM}$ malate and glutamate. (A) Representative traces of experiments displaying changes in $\mathrm{H}_{2} \mathrm{O}_{2}$ release by mitochondria without any addition (control, trace 4) or with addition of 1.4 (trace 3 ), $8.0 \mu \mathrm{mol} / \mathrm{mg} \mathrm{Ca}^{2+}$ (trace 1) or $10 \mu \mathrm{g} / \mathrm{ml}$ alamethicin (trace 2) in KCl-based buffer. (B) Calculations of the rate of $\mathrm{H}_{2} \mathrm{O}_{2}$ release by mitochondria exposed to calcium or alamethicin in KCl- and sucrose-based buffers. (C) Quantification of Cyt $\mathrm{c}$ release in experiments described above, expressed as percent of total Cyt c. ${ }^{*}$ and $(*)$ indicate significant difference compared to control using ANOVA and $t$-test, respectively, and \# indicates significant difference between calcium doses. (D) Electron micrographs of mitochondria captured following experiments in sucrose buffer. Double arrows indicate mitochondria with condensed cristae whereas single arrows illustrate mitochondria with more diffuse, expanded and sometimes disrupted cristae and outer membranes.

\section{Figure 3}

$\mathrm{H}_{2} \mathrm{O}_{2}$ generation in permeabilized brain mitochondria supplied with different respiratory exogenous substrates. Mitochondria were incubated in KCl-based buffer, initially without respiratory substrates. Representative traces of experiments displaying changes in resorufin (upper panel) and NAD(P)H fluorescence (lower panel). Following permeabilization with alamethicin (Ala, $10 \mu \mathrm{g} / \mathrm{ml}$ ), suspensions were supplemented with either $5 \mathrm{mM}$ succinate in presence of $2 \mu \mathrm{M}$ rotenone (trace 1), $5 \mathrm{mM}$ malate and glutamate (trace 3), $1.5 \mu \mathrm{M}$ NADH (trace 2) or $1.5 \mu \mathrm{M} \mathrm{NAD}^{+}$ (trace 4). In experiments with $\mathrm{NAD}(\mathrm{H})$ (trace 2 and 4), $5 \mathrm{mM}$ malate and glutamate (Mal/Glu) were administered where indicated. Inserted numbers in italic indicate mean rates of $\mathrm{H}_{2} \mathrm{O}_{2}$ generation ( $\mathrm{pmol} / \mathrm{min} / \mathrm{mg}$ mitochondria).

\section{Figure 4}

$\mathrm{H}_{2} \mathrm{O}_{2}$ release and NAD $(\mathrm{P}) \mathrm{H}$ redox status in respiring brain mitochondria exposed to respiratory inhibitors. Mitochondria were incubated in $\mathrm{KCl}$ buffer with $5 \mathrm{mM}$ malate and glutamate. Suspensions were exposed to $\sim 1 \mu \mathrm{M}$ antimycin (trace 1), $2 \mu \mathrm{M}$ rotenone (trace 2 ) or no addition (control, trace 3 ) and subsequently permeabilized with alamethicin (Ala, 10 $\mu \mathrm{g} / \mathrm{ml})$ where indicated. NADH $(1.5 \mu \mathrm{M})$ was added to rotenone and control groups at $12 \mathrm{~min}$. NAD(P)H fluorescence is displayed for control and rotenone experiments only as antimycin interfered with assay. Inserted numbers in italic indicate mean rates of $\mathrm{H}_{2} \mathrm{O}_{2}$ release ( $\mathrm{pmol} / \mathrm{min} / \mathrm{mg}$ mitochondria).

\section{Figure 5}

Changes in brain mitochondrial respiration induced by $\mathrm{mPT}$, calcium and alamethicin. Experiments in (A) were performed at $30^{\circ} \mathrm{C}$ using standard Clark-type electrodes and experiments in (B-D) at $37^{\circ} \mathrm{C}$ in high-resolution oxygraphs. Traces in (A) illustrate oxygen consumption of mitochondria oxidizing $5 \mathrm{mM}$ malate and glutamate. ADP (100 nmol) was added to induce a transient active phosphorylating rate of respiration. Calcium $(8.0 \mu \mathrm{mol} / \mathrm{mg}$, trace 1$)$ or alamethicin (Ala, $10 \mu \mathrm{g} / \mathrm{ml}$, trace 2) was added to induce mPT or unspecific permeabilization, respectively. A second administration of ADP was added to test for any remaining coupling of mitochondria. Inserted numbers in italic indicate mean rates of respiration (nmol/min/mg mitochondria). In order to correlate respiratory changes to the $\mathrm{H}_{2} \mathrm{O}_{2}$ generation induced by alamethicin and the different doses of calcium in Fig. 2, high-resolution respirometry of brain mitochondria was performed. Upper traces in (B) display oxygen concentration in suspensions of mitochondria oxidizing $5 \mathrm{mM}$ malate and glutamate exposed to indicated doses of calcium ( $\mu \mathrm{mol} / \mathrm{mg}$ mitochondria) or $10 \mu \mathrm{g} / \mathrm{ml}$ alamethicin. Lower traces illustrate respiration rate of mitochondria in the same experiments. Respiration rates were averaged over the indicated time spans and mean rates are depicted in (C), filled bars. * indicates significant difference compared to control and \# indicates significant difference between calcium doses. Comparisons of the respiration rates to detected $\mathrm{H}_{2} \mathrm{O}_{2}$ release rates are displayed in open bars and expressed as percent of $\mathrm{O}_{2}$ converted to $\mathrm{H}_{2} \mathrm{O}_{2}$. (D) Multiple substrate/inhibitor protocol in mitochondria permeabilized by alamethicin with (trace 1) or without (trace 2) calcium $(800 \mu \mathrm{M})$. Upper and 
lower traces depict oxygen concentration and respiration rates, respectively. Dashed lines indicate re-oxygenation of respiration chambers. Mitochondria were successively exposed to $200 \mu \mathrm{M}$ NADH, $5 \mathrm{mM}$ malate and glutamate, $2 \mu \mathrm{M}$ rotenone, $5 \mathrm{mM}$ succinate, $\sim 2.5 \mu \mathrm{M}$ antimycin and finally $2 \mathrm{mM}$ ascorbate and $0.5 \mathrm{mM}$ TMPD. No chemical background correction for autoxidative processes by ascorbate and TMPD was subtracted in the paired representative traces.

\section{Figure 6}

Loss of antioxidant scavenging function and accumulation of $\mathrm{H}_{2} \mathrm{O}_{2}$ in brain mitochondrial suspensions following mPT induced by bolus load or continuous infusion of calcium. (A) Mitochondria oxidizing $5 \mathrm{mM}$ malate and glutamate in $\mathrm{KCl}$ buffer were exposed to $8.0 \mu \mathrm{mol} \mathrm{Ca}{ }^{2+} / \mathrm{mg}$ (trace 1 and 3 ) or vehicle $\left(\mathrm{H}_{2} \mathrm{O}\right.$, trace 2 and 4 ) followed by $\sim 1 \mu \mathrm{M}$ antimycin (all traces) to enhance ROS generation. In order to assay the balance between mitochondrial $\mathrm{H}_{2} \mathrm{O}_{2}$ generation and removal, and whether there is a net accumulation of $\mathrm{H}_{2} \mathrm{O}_{2}$ in the mitochondrial suspensions independent of the scavenging by the detection system, HRP and Amplex Red were either administered at start (trace 1 and 2) or 7 min after calcium or vehicle (trace 3 and 4). In the latter experiments, suspensions of mitochondria which were exposed to a calcium bolus load demonstrated a rapid increase in resorufin fluorescence when the $\mathrm{H}_{2} \mathrm{O}_{2}$ reagents were added (trace 3) closely approaching the trace where the reagents were present from start (trace 1). In contrast, mitochondria not exposed to calcium started at a near zero level regardless of when HRP and Amplex Red were added (trace 2 and 4). (B) Experiments with delayed administration of HRP and Amplex Red were also performed in brain mitochondria exposed to a continuous infusion of calcium. Traces on the left side of the graph demonstrate changes in Fura $6 \mathrm{~F}$ fluorescence ratio reflecting extramitochondrial $\left[\mathrm{Ca}^{2+}\right]$. Mitochondria were infused with $0.2 \mu \mathrm{mol} \mathrm{Ca}{ }^{2+} / \mathrm{min} / \mathrm{mg}$ mitochondria, and the plateau level reflects a steady state where the infusion rate equals mitochondrial calcium uptake. Experiments were run in presence of $1 \mu \mathrm{g} / \mathrm{ml}$ oligomycin and either $200 \mu \mathrm{M}$ ADP (trace 5) or $1 \mathrm{mM}$ ADP and $1 \mu \mathrm{M}$ CsA (trace 6). The rapid increase in fluorescence of trace 5 represents calcium deregulation of mitochondria with release of retained calcium. Following calcium infusion, experiments were continued by assaying $\mathrm{H}_{2} \mathrm{O}_{2}$ generation. HRP and Amplex Red were added 6 min following antimycin administration, and mitochondria which had undergone a calcium deregulation demonstrated an immediately elevated level of resorufin fluorescence when the $\mathrm{H}_{2} \mathrm{O}_{2}$ reagents were added whereas mitochondria which had retained all calcium did not.

\section{Figure 7}

Inhibition of calcium-induced permeability transition (mPT) and $\mathrm{H}_{2} \mathrm{O}_{2}$ generation by cyclosporin analogs. (A) Quantification of $\mathrm{H}_{2} \mathrm{O}_{2}$ release of rat liver mitochondria over time run in an Amplex Red-based 96-well plate assay. Means \pm SD are shown for control experiments without calcium and for experiments with mitochondria exposed to 0.5 $\mu \mathrm{mol} \mathrm{Ca}{ }^{2+} / \mathrm{mg}$ in presence of $1 \mu \mathrm{M}$ cyclosporin $\mathrm{H}$, cyclosporin $\mathrm{C}$ or drug vehicle (ethanol). (B) Correlation between inhibition of calcium-induced $\mathrm{H}_{2} \mathrm{O}_{2}$ generation and inhibition of calcium-induced $\mathrm{mPT}$ under de-energized conditions for CsA and 21 cyclosporin analogs. Inhibition of $\mathrm{mPT}$ is expressed as percentage of that by CsA, all evaluated at $1 \mu \mathrm{M}$. Data is presented as a bivariate scattergram with regression analysis and $95 \%$ confidence intervals of mean. The identity of the analogs is listed in Table 1. 
Figure 1

A

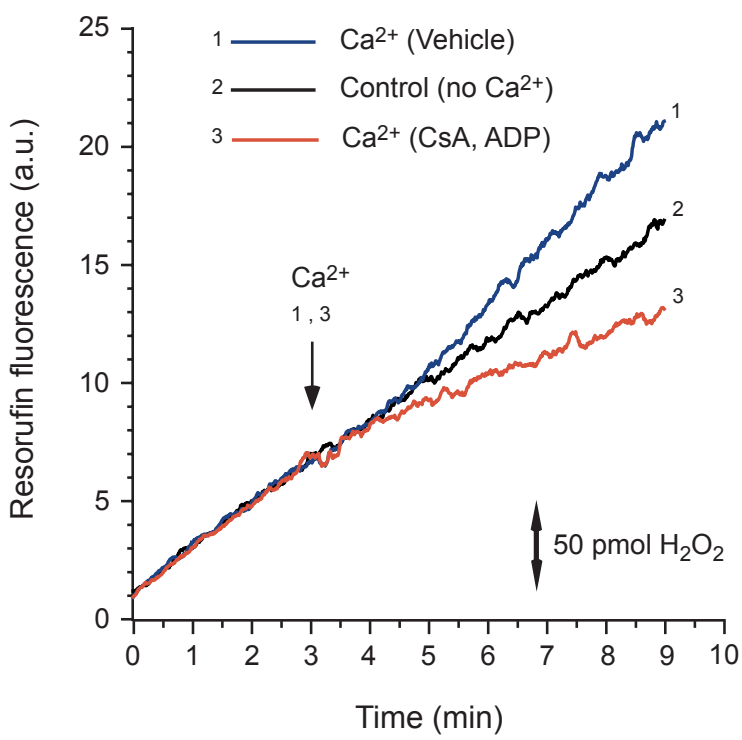

B

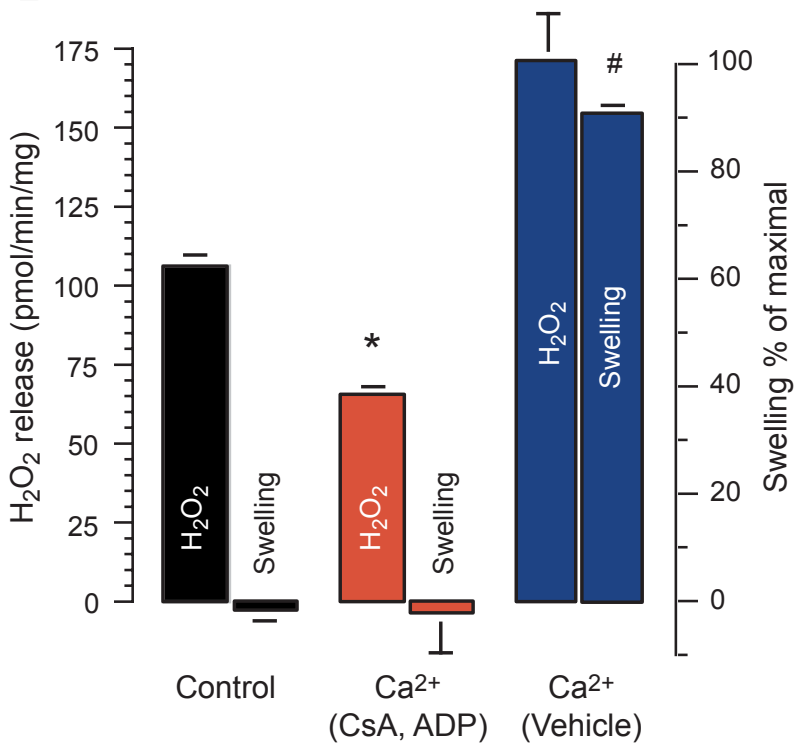

C

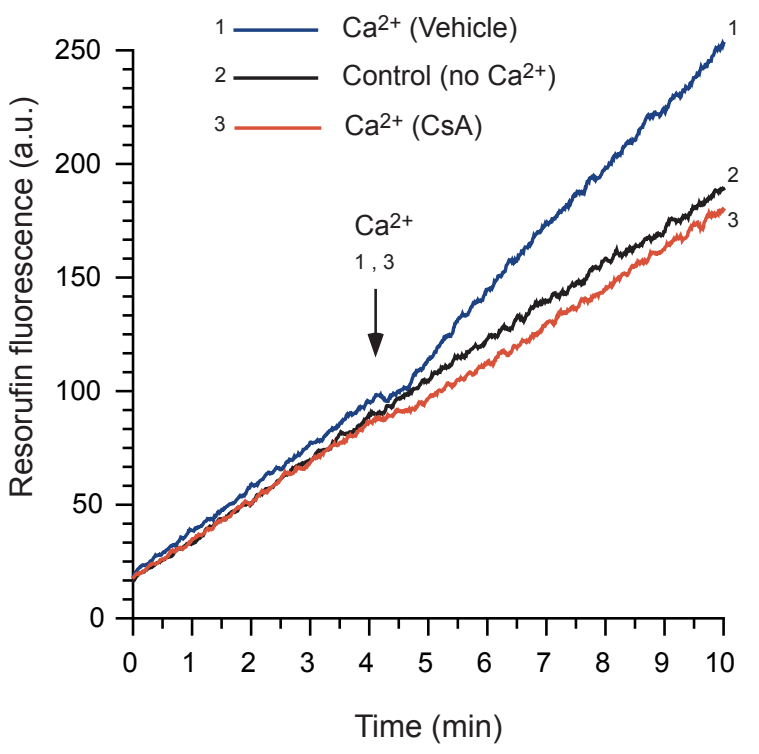


Figure 2
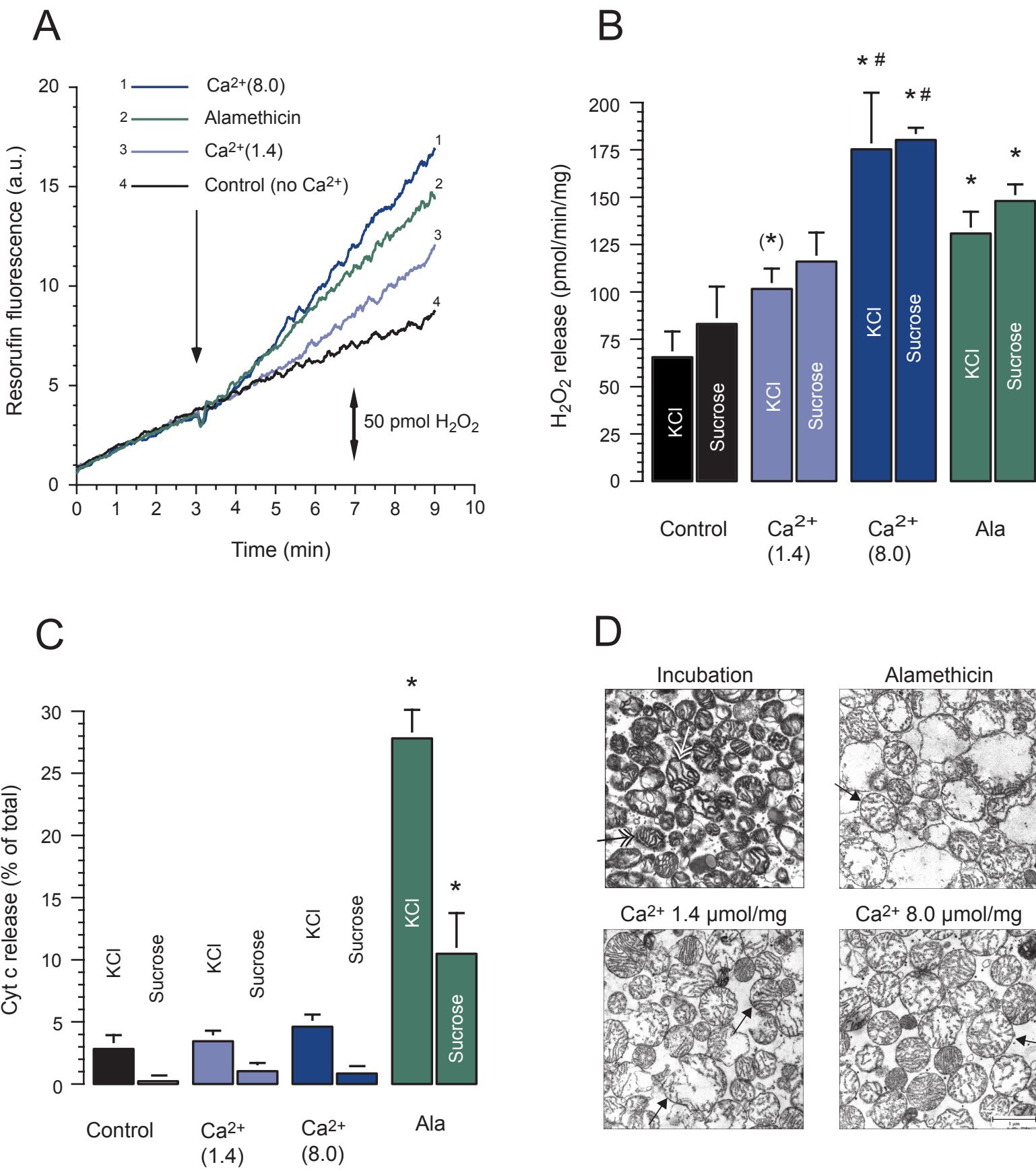

D
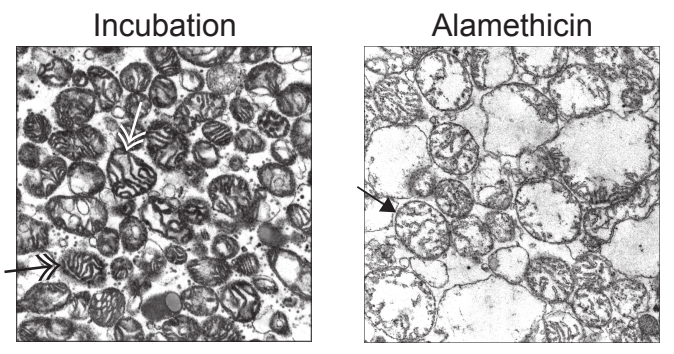

$\mathrm{Ca}^{2+} 1.4 \mu \mathrm{mol} / \mathrm{mg}$

$\mathrm{Ca}^{2+} 8.0 \mu \mathrm{mol} / \mathrm{mg}$
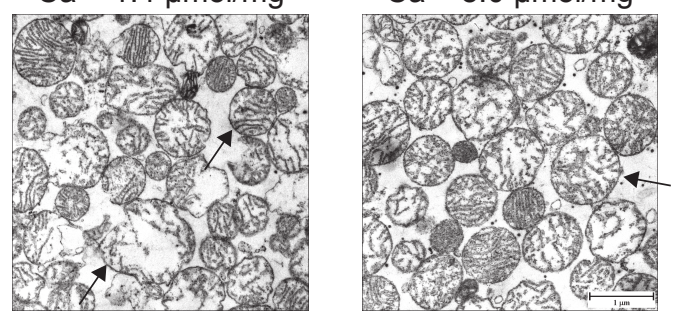
Figure 3

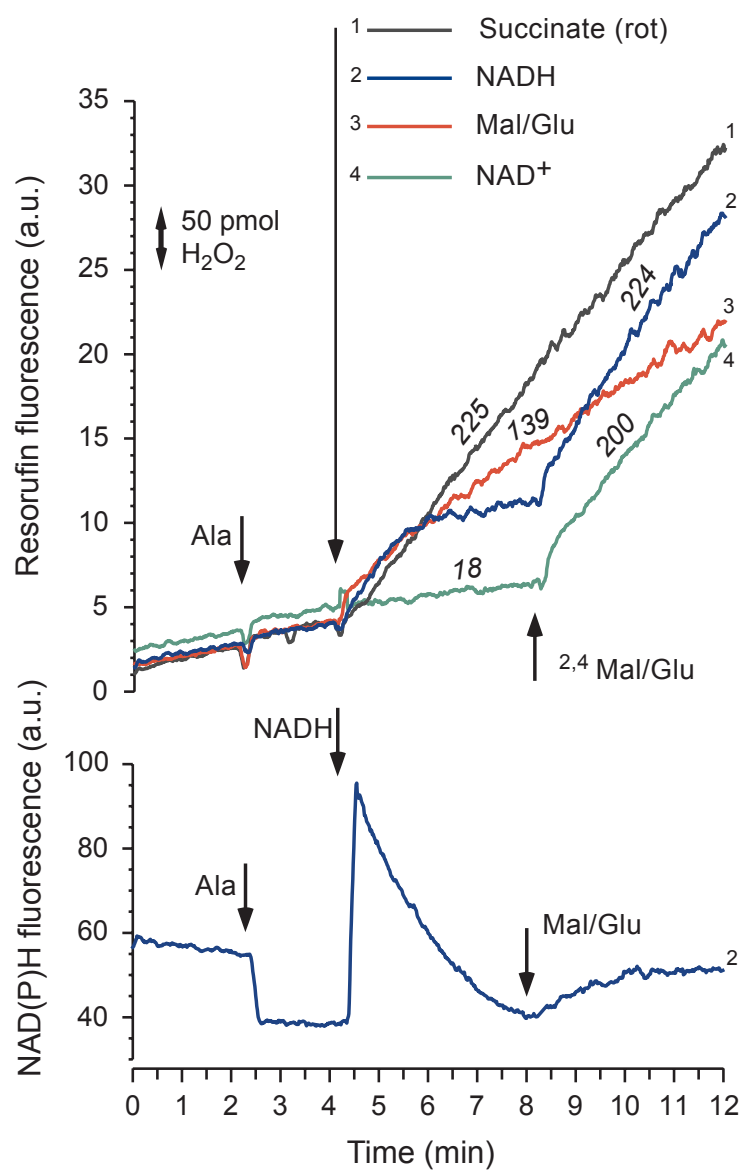


Figure 4

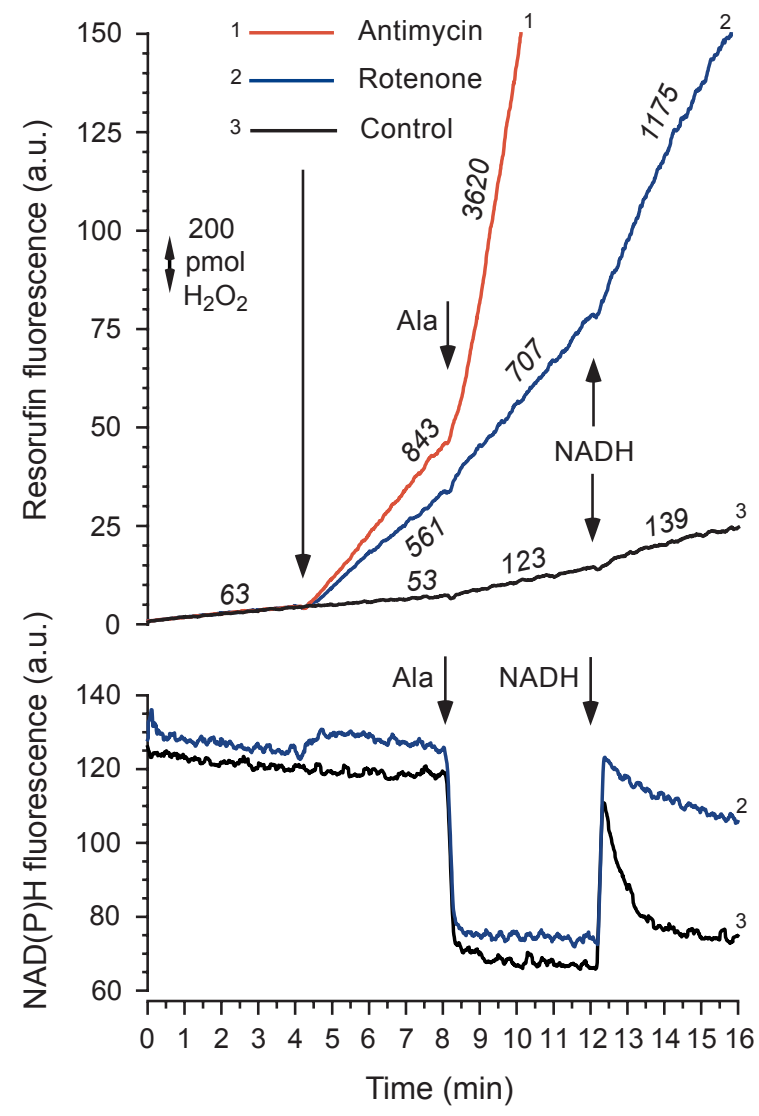


Figure 5
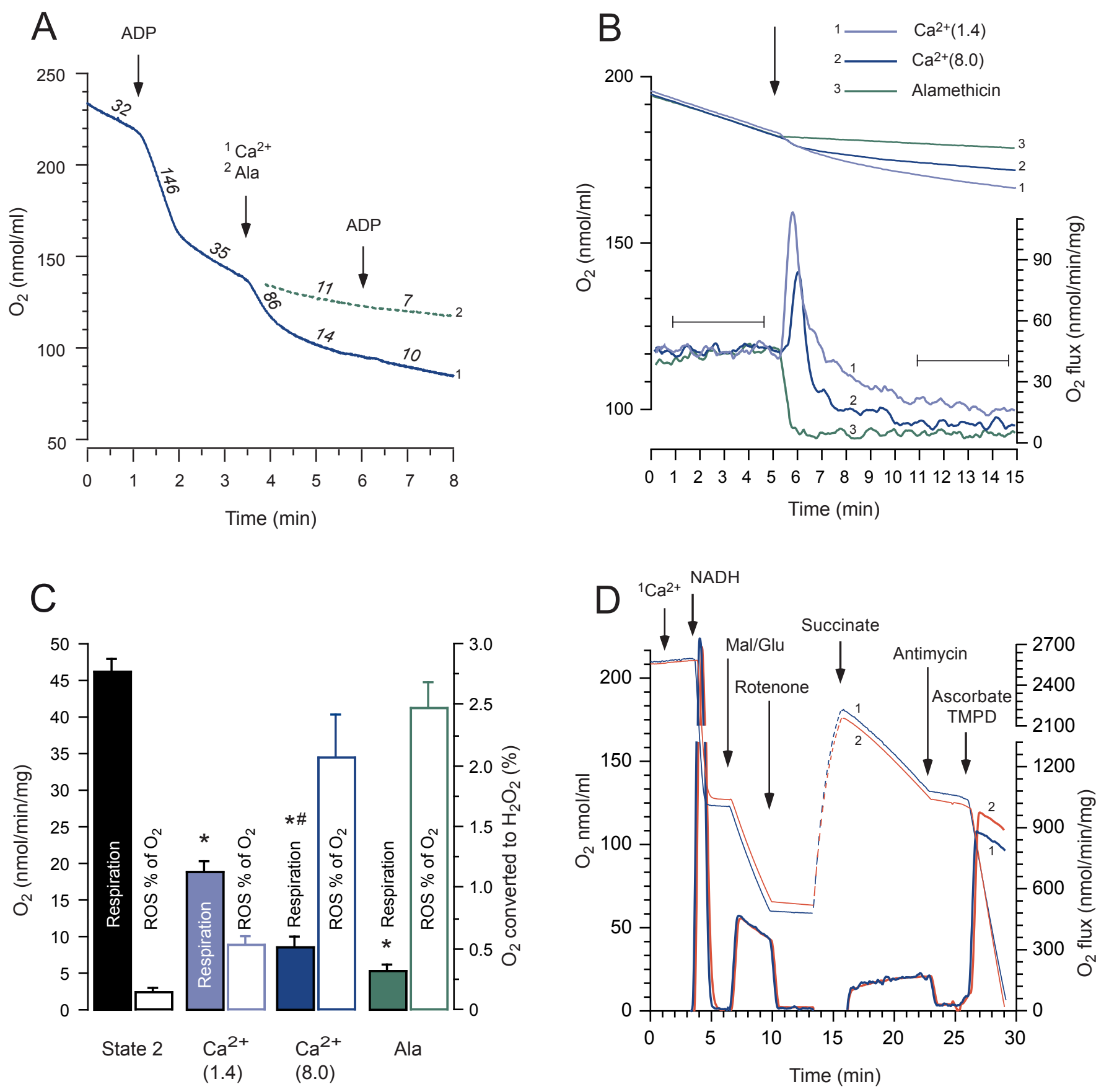
Figure 6
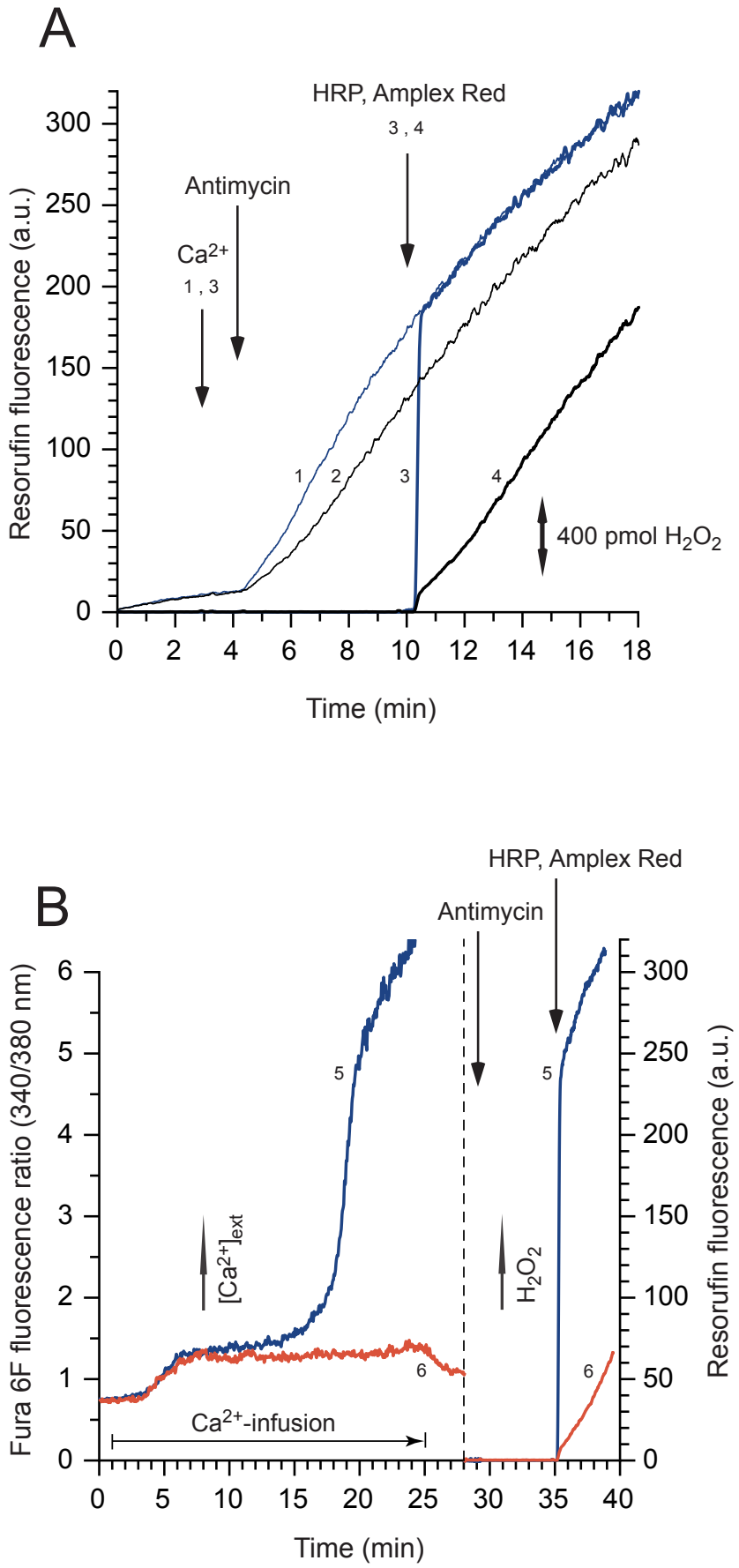
Figure 7

\section{A}

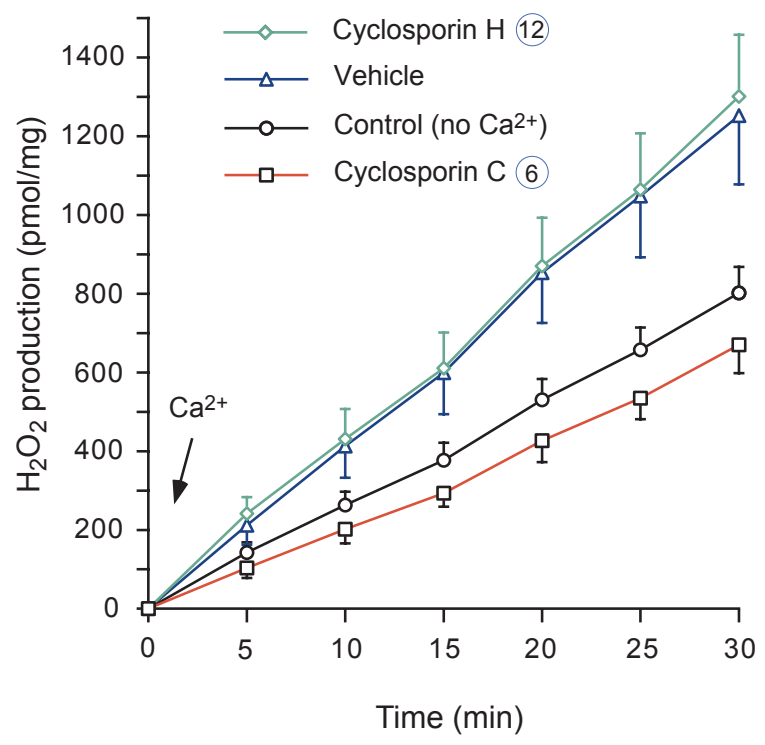

B

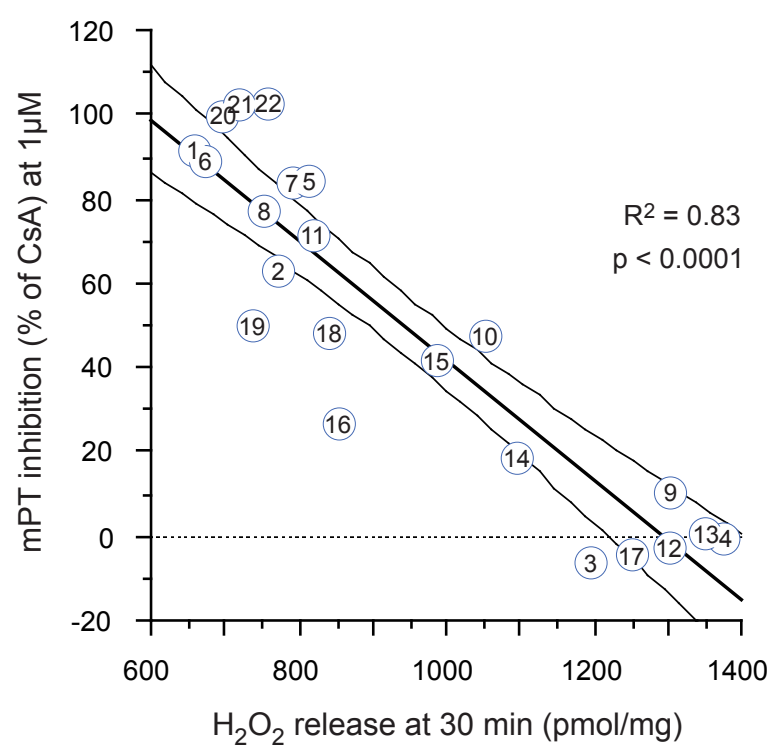

